\title{
ESTUDIO CLINICO DE ENFERMEDAD MIOCARDICA PRIMARIA
}

\author{
(Cardiomiopatía). Observaciones en 26 casos \\ Carlos Alberto Battilana Guanilo \\ Hospital "Dos de Mayo" y Hospital de Policia. Lima
}

\begin{abstract}
RESUMEN
Se han estudiado 25 paciontes con cardiomiopatia en el lapso de 10 años (19601970), originarios y provenientes de diferentes regiones del pais; 24 casos pertenecieron al sexo masculino y 2 al femenino. Trece pacientes correspondieron a la llamada cardiomiopatía idiopática, 8 estuvieron relacionados al alcoholismo, 3 fueron de lipo familjar, un caso de caraiopatia postpartum y atro con endomiocardiofibrosis. Las edades fluctuaron entre 13 y 65 años, con un promedio de 41.8 años.

Clínicamente, todos los pacientes, con excepción de uno, presentaron manifestaciones de insuficiencia cardiaca con hallazgos variados al examen físico, predominando la existencia de cardiomegalia, hipertensión venosa sistémica y ritmo de galope. En solamente un caso la sintomatología estuvo relacionada exclusivamen. te a embolismo múltiple. Las arritmias más frecuentes fueron de tipo extrasistólico, habiéndose demostrado fibrilación o flutter auricular en 5 casos. Los patrones electrocardiográficos fueron también variados, observándose de preferencia una combinación de bloqueo intraventricular con bajo voltaje; el electrocardiograma estuvo dentro de las límjtes normales en sólo un paciente, el cual falleció con cardiomegalia e insuficiencia cardíaca. La radiología demostró crecimienio cardíaco a predominio de cavidades izquierdas en, prácticamente, todos los casos.

Catcrce pacientes fallecieron, realizandose la necropsia en todos ellos. El es. tudio macroscópico del corazón fue anormal en 13 casos, mostrando dilatación e hipertrofia, sólo en un caso se halló un corazón de aspecto nolmal. Sin embargo, en todos los casos estudiados el examen histológico indicó alteraciones que principalmente comprometian a la fibra miocárdica, en forma de miocitolisis, alteraciones nucleares y cambios inespecificos en el tejido intersticial; estas alteraciones fueron consunes a muchos pacientes y no guardaron relación aparente con los diferentes cuadros clínicos. Las anormalidades de tipo ateroesclerótico o inflamatorio fueron insignificantes.
\end{abstract}

Se ha considerado a la cardiomiopatía como una entidad clínica caraclerizada por: insuficiencia cardiaca congesti. va, cordiomegalia, anormalidades electrocardiográficas y alteraciones hemodinámicas, que afecta de preferencia al miocardio y de origen generalmente desconocido $(61,62,73,94,95)$.
Desde un punto de vista nominal, la cardiomiopatía es también conocida como: hipertrofia cardiaca de origen desco. nocido $(86,88)$, enfermedad miocárdica de origen oscuro (136), hipertrofia miosárdica con degeneración e insuficiencia de origen desconocido (110), fibrosis del endocardio y del miocardio con trom- 
BATTLANA G., C. A. Estudio Clínico de Enterm suaji Miocórdica Primaria (Cardiomiopalía). Observaciones en 26 casos. An. Med. Univ. N. M. S. M. 54 (3): 262-305, 1971.

bosis mural (124), hipertrofia cardíaca masiva (43), miocarditis crónica fibroplástica (138), hipertrofia miocárdica idiopática $(87,115,139)$, enfermedad miocárdica primaria $(45,58)$, enfermedad hipertrófica del miocardio (116), cardiomegalia idiopática (57), hipertrofia idiopática del ventrículo izquierdo (125), hipertrofia idiopática cardíaca (20), cardiomiopatía idiopática (16), enfermedad del corazón de etiología desconocida (42), cardiomiopatía oscura (39), miocardosis (15). Esta gran diversidad de sinónimos que presenta la cardiomiopatía, es la expresión del conocimiento in. suficiente que de ella se tiene en la actualidad.

La evolución del pensamiento médico en relación a las enfermedades del miocardio, ha sido muy bien tratado por Mattingly (96), en cuya revisión es posible ver la influencia de los cambios conceptuales en la apreciación patogénica $y$ en el diagnóstico de las enfermedades miocárdicas.

El conocimiento de la cardiomiopatícr ha pasado por etapas que empezaron en el siglo pasado con la contribución de diferentes autores, entre los cua les cabe mencionar a Friedrich (63), que utilizó el término "hipertrofia idiopática" para un proceso que se presentaba principalmente en trabajadores manuales de sexo masculino y que consumín grandes cantidades de alcohol, también importan. te fue lo descrito por Strümpell (129) en 1881, en relación a casos de insuficien. cia cardíaca que en la autopsia mostraron solamente hipertrofia y dilatación de las cavidades; en 1893 Graham Steell (128), hizo mención a 25 casos de insu- ficiencia cardíaca que los atribuyó al alcoholismo crónico. En 1901, Josserand y Galavardin (82), describieron tres casos de insuficiencia cardíaca progresiva en sujetos jóvenes debido a miocaraitis subaguda primaria, "La descripción clínica y la autopsia de estos casos contienen muchos de los elementos que en la actualidad se consideran característicos de la cardiopatía o enfermedad miocárdica primaria: cardiomegalia, trombosis mural y embolismos con fibrosis intersticial $y / O$ degeneración de la fibra miocárdica; Laubry y Walser (85) en 1925, publicaron el caso de un paciente de 15 años que murió en insuficiencia cardíaca de rápida evolución, hallándose en la autopsia solamente dilatación e hipertrofia con un miocardio "pálido y descolorido"; histológicamente no se encontraron lesiones en las fibras o en el iniersticio, solamente ligero edema intersticial, por lo que los autores pensaron que el trastorno era fundamentalmente de tipo funcional, sugiriendo el término "miocardia" para estos casos. A partir de 1930, empieza una era de estudio sistemático de las enfermeda. des del corazón, que se traduce en la publicación de algunos textos de cardiología que trajeron consigo un considerable avance en esta rama de la medicina interna, pero con toda la sistematización racionalizada que se ve aún en los textos de fecha reciente, no deja de llamar la atención la ausencia relativa de una descripción de los procesos miocórdicos crónicos o cardiopatías, entidades que como hemos dicho, a pesar de las descripciones aisladas de años anieriores, son un problema cuya importancia recién se ha venido a enfatizar en la década pasada. 
Battilana G., C. A. Estudio Clínico de Enfermódad Miocárdica Primaria (Cardiomiopalía), Osservociones en 26 cascs. An. Med. Univ. N. M. S. M. 54 (3): 262-305, 1971.

En el Perú el estudio de las cardiomiopatías se derivó del interés inicial por la miacarditis chagósica, desde que, en 1917, Escomel (48), describiera el primer caso de tripanosomiasis en el Perú; en 1958, Rafael Alzamora (7) publica el primer caso de miocarditis chagásica estudiado en 1928, ounque recién reportado en 1958. Fue la motivación por el estudio de este tipo particular de miocarditis lo que originó, posterjormente, las diferentes encuestas epidemiológicas en diferentes regiones del pais que se tradujeron en varios trabajos por parte de Peralta y col. (103) y Comejo Donayre y col. (36), con resultados que indicabon una escasez relativa de la cardiopatía chagásica. La experiencia obtenida de estos estudios, sumada a la información llegada en publicaciones extranjeras, es lo que ha permitido que el diagnóstico de enfermedad miocárdica se considera con más trecuencia en nuestro medio. Contribuciones importantes también han sido las de Romero (112) y Repetto (111). sobre patología predominantemente en. docárdica; un trabaio reciente es el de Liro (90), al presentar como parte de un estudio principalmente anátomo-patológico 3 casos de cardiopatía de etiología oscura.

Se ha escogido a la cardiomiopatía como tema de este irabajo por ser ella una patología de palpitante actualidad, y distribución mundial, y cuyo conocimiento, como se ha mencionado, es todavía insuficiente; aparte de que nuestro trabajo, al describir las características clínicopatológicas de un grupo de pacientes con cardiomiopatía, contribuye a un conoci. miento más amplio de la patología car- diovascular en el Perú. Este tema tiene proyección mundial, como se deduce de varios trabajos provenientes de diferentes regiones del globo $(42,53,73,82,85$, 95). siluación que ha movido o la Sociedad Internacional de Cardiología a constituir un "Consejo de las Cardiomiopatías" y a publicar una monografía al res. pecto (81).

Para los fines de este trabajo, se ha agrupado a la casuística bajo la clasificación que Harvey y colaboradores (77) han recomendado para las cardiomiopatías, estos autores las dividen en dos grandes grupos: Idiopáticas y específicas, considerando para este último sólo aque. llos cosos en los cuales es posible demostrar una etiología. Es necesario adelantar que existen numerosas clasificaciones de las cardiomiopatías (62, 95, 125), según los criterios de los autores que más han trabajado en este tema; esta abundancia de clasificaciones así como de sinonimia, es un hecho que ha contribuido más bien a crear confusión y dificultar el conocimiento de estas enfermedades.

\section{MATERIAL Y METODOS}

Material: El presente trabajo ha sido realizado en 26 pacientes, de los cuales 22 han sido estudiados en el Hospital Dos de Moyo en el lapso de 11 años (19591970). Como este hospital era tradicionalmente para hombres, es este el motivo por el cual todos estos pacientes son del sexo masculino; en el hospital de las "Fuerzas Policiales" se estudiaron tam. bién dos casos, ambos de sexo masculino. Dos pacientes de nuestra casuística 
BATTILANA G. C. A. Estudio Clínico de Enferm sciad Víocárdica Primaria (Cardiomiopalía). O'sservaciones en 26 cases. An. Med. Univ. N. M. S. M. 54 (3): 282-305, 1971.

pertenecen al sexo femenino, casos 21 y 22, la paciente del caso 21 falleció en el Hospital Sto. Toribio de Mogrovejo y ha sido considerada por su relación fraterna con dos pacientes (Casos 4 y 20 ), que yor estaban en estudio; el Caso No 22 es de una paciente procedente de Chincha, traída en interconsulta por su médico tratante, siendo incorporada al grupo. Además se ha tomado en cuenta, sólo para tines de la discusión, a un caso que falleció en el Hospital Obrero de Lima, por su relación familiar con tres pacientes de la casuística presentada (casos Nros. 4, 20 y 21 ).

Métodos: La selección de los casos se realizó siguiendo los criterios propug. nados por Fowler (58), que exigen:

a) Presencia de cardiomegalia y/o insufitiencia cardíaca congestiva.

b) Ausencia de hipertensión diastó. lica por encima de $100 \mathrm{mmHg}$.

c) Ausencia de clínica de enfermedades renales tales como: glomerulonefritis en cualquiera de sus formas, lupus eritematoso y esclerodermia.

d) Ausencia de anemia, tirotoxicosis, avitaminosis o mixedema.

e) Ausencia de enfermedad significativa pulmonar, enfisema, fibrosis pulmonar, sarcoidosis, embolismo pulmonar crónico recurrente.

f) Ausencia de enfermedad cardio. vascular, congénita o adquirida, principalmente cardiopatía reumática o cardio. esclerosis.

Todos los pacientes para ser incluidos en el presente trabajo fueron previa- mente sometidos a un estudio clínico que comprendió:

1. Anamnesis, precisando las características de la enfermedad y la existencia de antecedentes alcohólicos o de alguna cardiopatía que explique el cuadro.

2. Examen lísico general.

3. Evolución de los aspectos clíni$\cos$ y la respuesta al tratamiento.

4. Exámenes de laboratorio rutinarios, que se realizaron en la mayoría de los pacientes, habiéndose llevado a cabo también algunos especializados como: reacción de fijación de complemento para enfermedad de Chagas (Casos Nros. $1,2,3,4,5,6,7,11,14,15)$, para toxo. plasmosis (Casos Nros. 14 y 15), xenodiagnóstico (Casos Nros. 6 y 7), células L.E. en tres casos ( 4,7 y 15$)$, finalmente reacciones serológicas para lúes en 16 casos; también se llevaron a efecto análisis bioquimicos relacionados al higado como: bilirrubinas en 15 pacientes, transaminasas en 9, pruebas de flocula. ción y turbidez en 11 , proteínas totales y traccionadas en 14 pacientes, colesteroi en 7 , se realizaron también otras pruebas según las necesidades particulares de cada caso.

5. Electrocardiogramas con doce derivaciones y con la técnica standard, se registraron en 26 casos. La interpretación fue de tipo convencional, siguiendo criterios cualitativos y cuantitativos, como los recomendados por Massie y Walsh (93). Fonocardiogramas también con téc. nicas standard en 4 casos.

6. El estudio radiológico de corazón se realizó en todos los pacientes en forma de telerradiografías en posición frontal, 
BATTILAN G., C. A. Estudio Clínico de Enlerminad Miocóndica Primaria (Cardiomiopatia). Observaciones en 26 casos. An. Med. Univ. N. M. S. M. 54 (3): 262-305, 1971.

en 18 casos se incluyeron las oblicuas anterior izquierda y anterior derecha. En la mayoría de los casos se procuró realizar el estudio radiológico una vez que el paciente alcanzaba la compensación cardíaca, por lo que solamente en tres pacientes fue posible hacer una evolución radiológica del curso clínico.

7. El cateterismo cardíaco del lado derecho del corazón fue llevado a cabo en 5 pacientes con la técnico habitual. aunque un informe cuantitativo de éstos figura en sólo cuatro casos, la procedencia de este método auxiliar fue considerada también en otros pacientes pero fue finalmente diferida en razón a la condición clínica del caso.
8. Se pudo reclizar un estudio anatomopatológico en 14 corsos, comprendiendo el examen macroscópico de la pieza y estudio microscópico con coloracio. nes corrientes $y$ especiales para fibras colágenas, elásticas y mucopolisacáridos (Van Gieson, Gomöri y PAS respectivamente).

\section{RESULTADOS}

Edad: La edad promedio fue de 41.8 años, habiendo sido 13 y 65 años las eda. des extremas de la serie; en el Cuadro No 1 puede apreciarse que de los $26 \mathrm{ca}$. sos, 19 estuvieron comprendidos entre 30
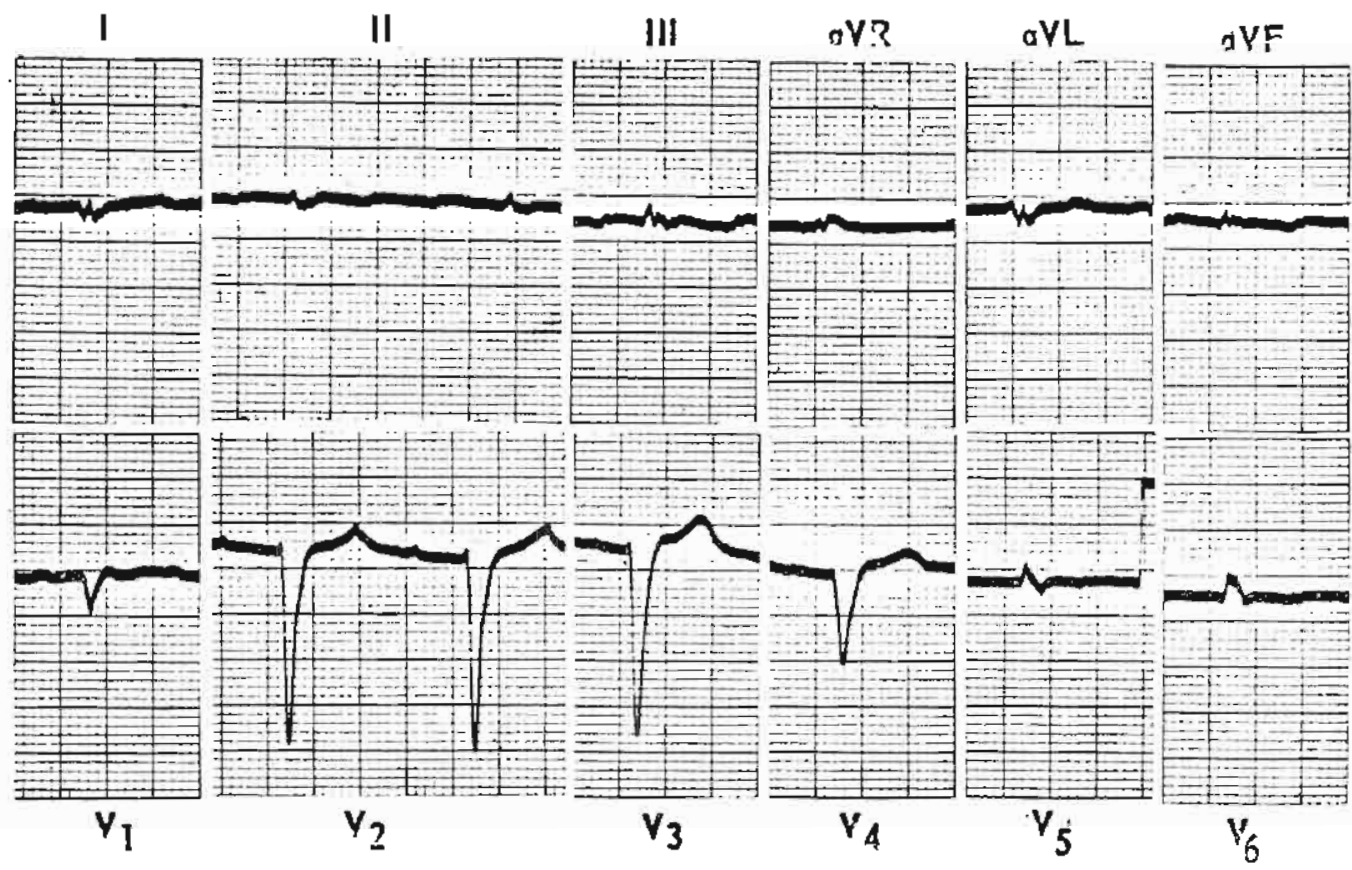

Fig. 1. Caso No 4: Electrocordiograma, del 6.1.60. Ritmo quricular. Bloqueo quriculo-ventricular variable 4:3, 3:2. Frecuencia auricular 225, ventricular promedio 68/min. Notable reducrion del volta:e en las derivaciones de los miembios $y$ precordiales $V_{0}: V_{i j}$; dellexiones amplias en $V_{2}$ y $V_{3}$. Bloqueo de roma izquierdo $(0.12)$. con ele de CRS en $+150^{\circ}$. 
Battilana G., C. A. Estudio Clínico de Enimm edad Micárdica Primara (Cardiomopatía). Observaciones on 26 casos. An. Med. Univ. N. M. S. M. 5A (3): 262.305, 1071.

y 60 años, lo que hace un $73 \%$, cinco casos debaio de treinta, y dos encima de sesenta años, lo que arroja $19.2 \%$ y $7.8 \%$ respectivamente.

Sexo: 24 pacientes ( $92 \%$ ) fueron del sexo masculino y solamente dos $(8 \%)$ fueron del sexo femenino, cabe mencionar que esta cifra no es representativa por los motivos ya expuestos en la presentación del material, (ver Cuadro No 1 ).

Raza: 25 pacientes (96\%) fueron mestizos y solamente uno de raza blanca cuyo origen era eslavo.

Lugar de origen: Seis pacientes nacieron en Lima, tres en La Libertad, Junín y Ayacucho, dos en Lambayeque e Ica, Y uno en Piura, Cajomarca, Cerro de Pasco, Huánuco, Arequipa, San Marlín, Amazonas.

Lugar de procedencia: 17 pacientes procedían de Lima, 2 de La Libertad, 2 de Ica, uno de Ayacucho, uno de Apurimac, uno de Amazonas y uno de Junín.

Hábitos: 8 casos, que representan el $30.7 \%$, fueron alcohólicos, ingiriendo en forma excesiva pisco, cerveza y cañozo - chicha, con un tiempo promedio de ingesia de 22.8 años para 5 casos que figuron con datos precisos en las historias.

Estado de nutrición: Como se verá más adelante, en el examen físico, ningún paciente mosiró signos de déficit vitominico.
Manitestaciones iniciales: El tiempo de enfermedad promedio antes de la primera consulta tue de 9.9 meses. En 24 casos o sea el ( $92.2 \%)$, las primeros monifestaciones fueron de insuficiencia cardíaca, en un caso el cuadro comenzó con fenómenos embólicos $y$ en oiro caso con una dolencia gastrointestinal.

Sintomas: Los tres sintomas más írecuentes fueron: disnea en 24 casos $(92.3 \%)$, edema en $19 \operatorname{cosos}(73 \%)$, y ios en 13 casos $(50 \%)$, cabe mencionar que en 11 casos $(42.3 \%)$, se presentó expectoración hemoptoica en algún momenio de la enfermedad. El promedio de durcción de los síntomas, desde el inicio de la enfermedad hasla la muerte, fue de 17 meses en los 14 casos que falle. cieron.

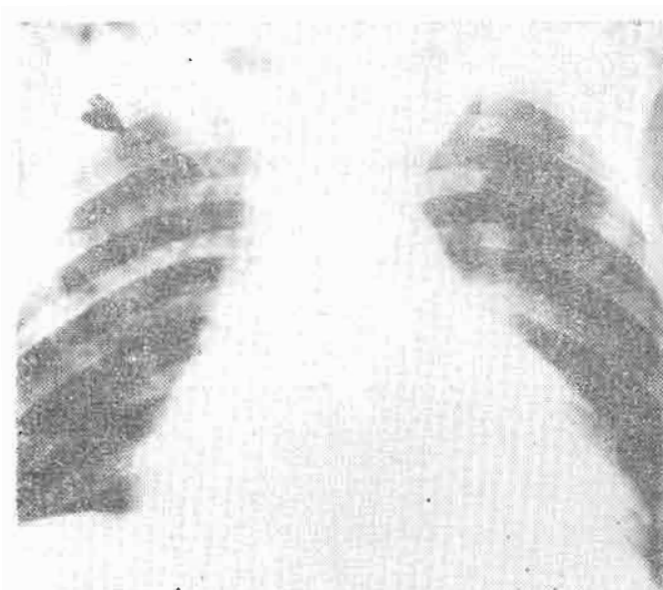

Fig. 2. Caso N" 4: Telmradiogratia del corazón, 22.1.60. se puede apreciar agraniamiento cardiaco global. 
BatTilanA G., C. A. Estudio Clínico de Enfermədad Miocárdica Primaria (Cardiomiopatía). Observaciones en 26 cosos. An. Med. Univ. N. M. S. M. 54 (3): 262-305, 1971.

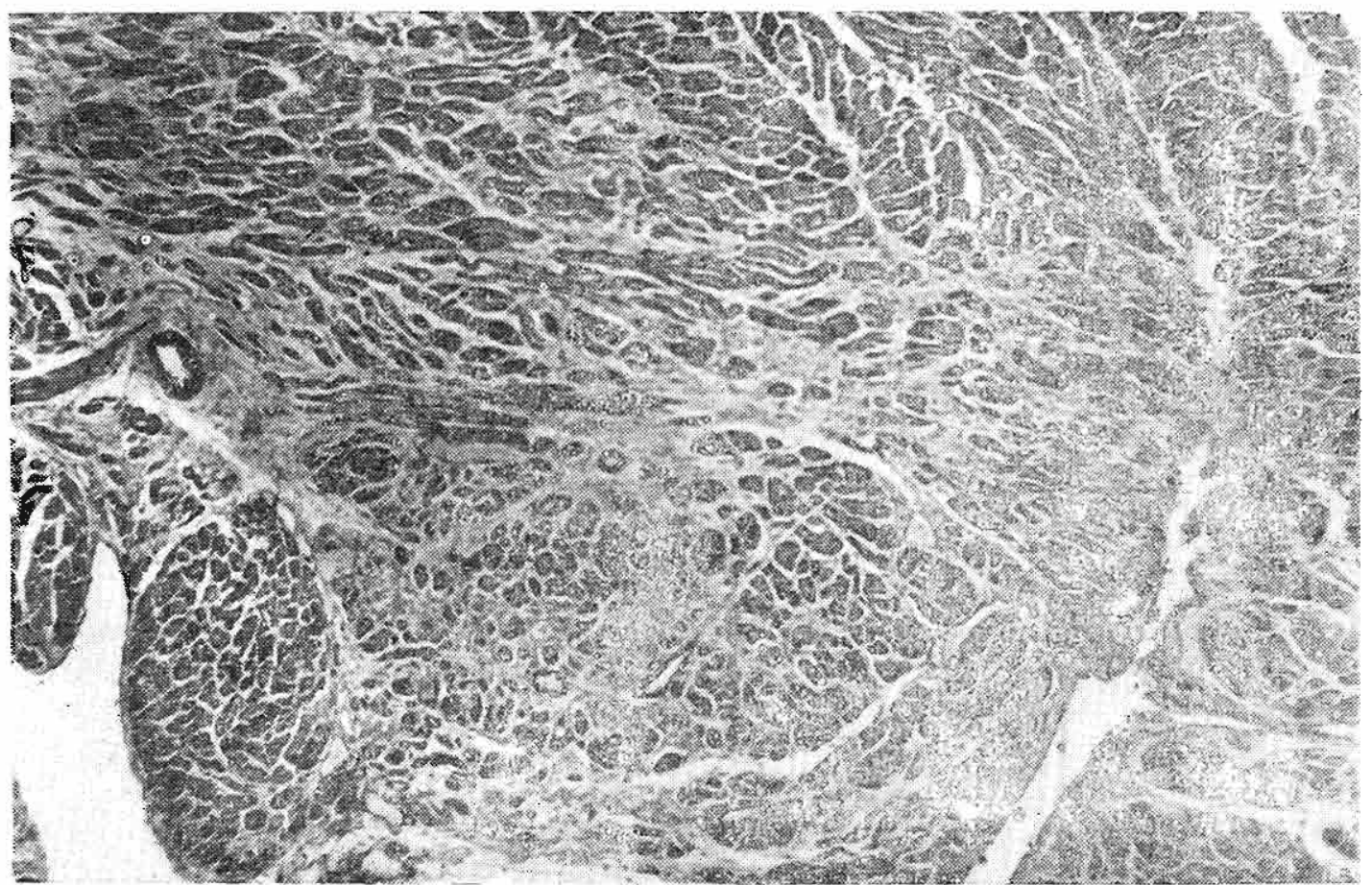

Fig. 3. Caso $N^{0} 4$ : Autopsio $N^{0} 2089$ (Hospital Dos de Mayo). Visla panorámica de una sección del miocardio subendocárdico, mostrando hipercromatismo nuclear y miocitolisis con aumento del intersticio paro sin fibrosis. (H.E. X35).

Examen físico: La frecuencia cardíaca promedio en el período de estado ha sido de $93 \mathrm{lat} / \mathrm{min}$; asimismo el mecanismo cardíaco fue irregular en 7 casos, y como se verá a propósito de los electrocardiogramas, esta irregularidad se debió a que 3 pacientes ienían fibrilación auricular; dos tenían flutter auricular y 2 extrasistolia ventricular. La presión arterial promedio sistó. lica y diastólica fue de 114 y $80 \mathrm{mmHg}$ respectivamente, con una diferencial promedio de $34 \mathrm{mmHg}$. Se debe anotar que en 3 pacientes se presentó hipertensión arlerial diastólica, (casos Nos. 8, 9 y 22). Los tres hallazgos físicos más frecuen. tes fueron: hepatomegalia en 21 casos, lo que representa ( $81 \%$ ), cardiomegalia y edema, ambos con 18 casos, lo que arroja (69\%) respectivamente. Los hallazgos cardiovasculares más saltantes fueron: 18 casos $(69 \%)$ con desplazamiento del apex por fuera de la línea media clavicular, 16 casos presentaron ingurgitación yugular a $90^{\circ}(62 \%), 14 \mathrm{ca}$ sos (54\%) presentaron galope, de los cuales 11 eran ventriculares, dos auricu- 
BATTILANA G., C. A. Estudio Clínico de Enfermedod Miocárdica Primaria (Cardiomiopatía). Observaciones en 26 casos. An. Med. Univ. N. M. S. M. 54 (3): 262-305, 1971.

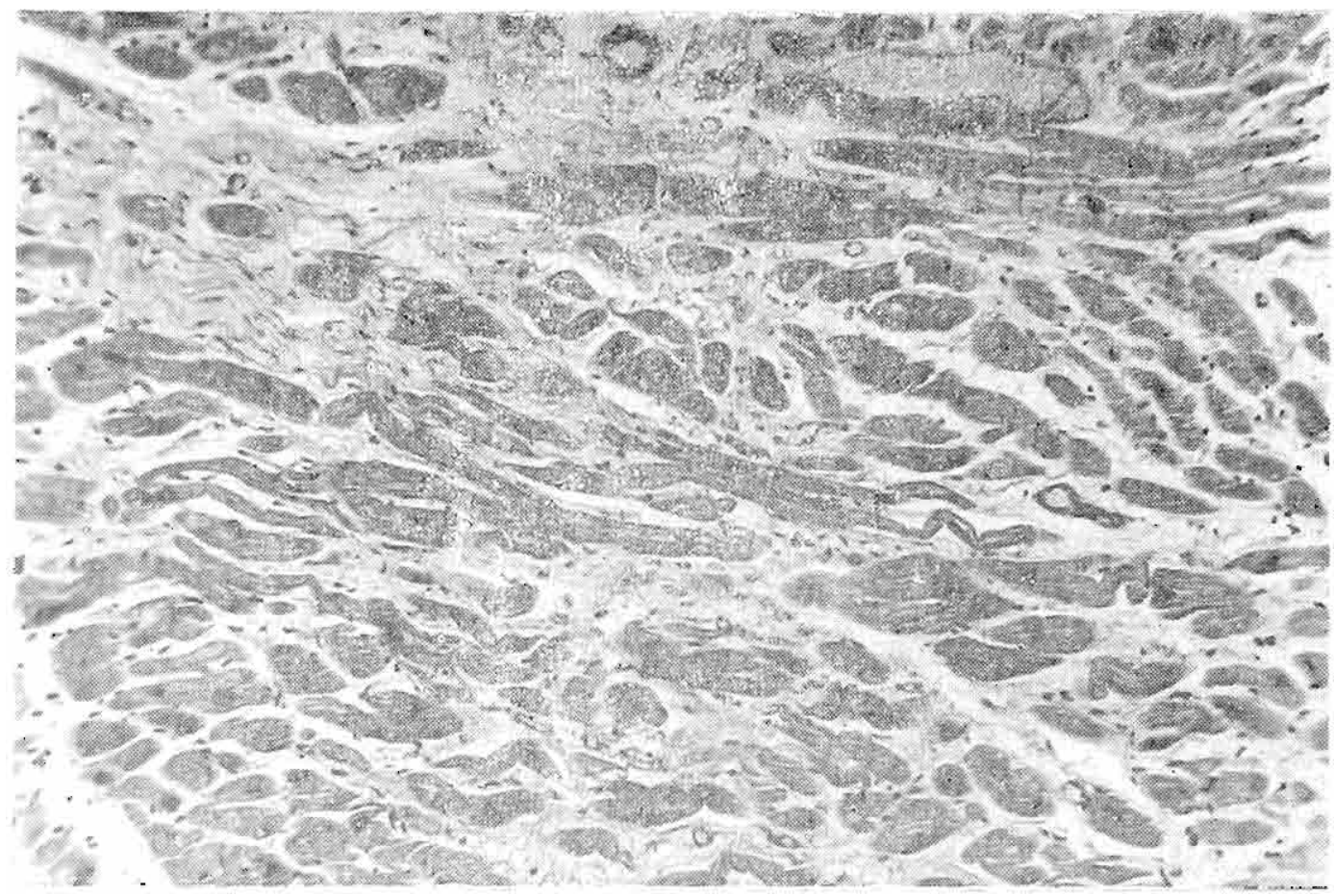

Fig. 4. Caso N 4: Aulopsia No 2089 (Hospital Dos de Mayo). A mayor aumenlo se observa tragmentación parcial de las fibras miocárdicas, hipercromatismo nuclear y el inlersticio aumentado. En el cuedrante superiar izquierdo se observa una extensa zona de miociololisis. con restos miofibrilares. Discrelo infittado $a$ celulas redondas. (H.E. XlOO).

lares y uno de suma. En los casos 22 y 24 el galope desapareció con el tratamiento, persistiendo en los demás. En 11 casos se ouscultaron soplos, todos sistólicos, los cuales se percibieron con ma. yor clarialad en el área mitral, solamente en l caso, No 13, el soplo se percibió mejor en el foco tricuspídeo; en los casos l y 22 la intensidad del soplo disminuyó considerablemente con la compensación cardíaca, en el caso No 23 el sopio se auscultó cuando la frecuencia cardíaca disminuyó a $100 /$ min. con el tratamiento, en el caso No 24 se cuscultó un soplo ho- losistólico de alta frecuencia, pero en la necropsia no se encontró lesión valvular orgánica.

Ninguno de los pacientes presentó soplo diastólico. La intensidad de los ruidos cardíacos fue normal en 10 casos, o sea el $(38.4 \%)$, o se cuscultó disminuida en 10 casos (38.4\%), y en 6 no figuron datos particulares en las historias clínicas.

Ningún paciente mostró al examen físico signos de desnutrición, avitaminosis o cmemia, salvo el caso $N^{\circ} 4$, que en 
BATTILANÁ G., C. A. Estudio Clinico de Enlermadad Miocárdica Primaria (Cardiomiopatía), Ob. serpaciones en 20 casos. An. Med. Univ. N. M. S. M. S4 (3): 282-305. 1971.

la fase terminal de la enfermedad desarrolló unc acentuada caquexia.

La evolución y respuesta al tratamiento se puede crpreciar en el grático No 3 .

Exámenes de laboratorio: Las pruebos rutinarias de laboratorio fueron normales en todos los pacientes en quienes se realizaron, aunque cuatro pacientes presentaron leucositosis, en ninguno de ellos, ni en la serie total, se encontró eosinofilia. Las pruebas de fijación de complemento para la enfermedad de Chagas fueron negativas en todos los pacientes en los cuales se practicaron. En dos casos solmmente la reacción de Sabin $y$ Feldman fara toxoplasmosis fue positiva $1 / 16$ y $1 / 32$, asimismo, las pruebas serológicas para lúes, cuantitativas y cualitativas, fueron negativas en todos los casos investigedos. En ninguno de los catorce casos en los cuales se practicó el dosaje de proteínas totales y fraccionadas, se encontró alteración de éstas como reflejo de un trastorno hepático $\mathrm{y} / \mathrm{O}$ nutricional, otras pruebas bioquímicas de explo. ración hepática arrojaron hiperbilirrubinemia en 8 pacientes, elevación de las transaminasas muy discreta, principalmente la glutámico-pirúvica en 9 pocientes, solamente tres pacientes mostraron pruebas de floculación y turbidez positiva, asimismo $e l$ colesterol fue normal en todos los pacientes en los que se dosó. Las determinaciones de úrea y creatinina y el examen de orina arrojaron datos negativos en todos los casos.

Electrocardiograma: 16 pacientes presentaron arritmias por formación del impulso en forma de fibrilación auricular, flutter auricular o exirasístoles ventriculares. Las alteraciones en la conducción $\mathrm{A}-\mathrm{V}$ se registraron como bloqueo aurículo-ventricular de primer grado en dos casos (No 20 y 21), por el contrario, en el caso No 1 la conducción A-V estuvo más bien acelerada sin llegar a tener las características de un Wolff-ParkinsonWhite típico, pues no se regisiró onda Del$t \alpha_{i}$ esta conducción acelerada podría explicarse por la presencia de una fibra pa. ra-específica muy vecina al sistema do conducción A-V (44). No se encontró ningún ejemplo de bloqueo avanzado aurículo-ventricular. Se registraron trastor. nos de la conducción intraventricular en 14 casos, de los cuales 3 ( N 7,10 y 17) presentaron las características del bloqueo de la rama derecha del haz de His, en 8 pacientes el bloqueo fue del tipo de la rama izquierda, y es interesante anotar que en cuatro de ellos (Casos Nros. 4 , 11,16 y 19) el eje estuvo hacia la derecha en el plano frontal, en dos casos se Iegistró, además del bloqueo de la rama derecha, una marcada desviación del eje de QRS en el plano frontal hacia la izquierda, asociación que ha sido descrita como bloqueo de la rama derecha con bloqueo de la subdivisión ántero superior de la rama izquierda (113), solamente en un caso el No 2 se encontró esta últi. ma modalidad de hemibloqueo de la rama derecha. Otros dos pacientes (Casos Nros. 7 y 17) presentaron esta combinación, pero no fueron considerados porque concomitantemente mostraron imágenes de necrosis.

La orientación del vector media de 
BATTILANA G., C. A. Estudio Clínico de Eniorm siad Miocárdica Primaria (Cardiomiopatía). Ob. sarvaciones en 26 casos. An. Med. Univ. N. M. S. M. 54 (3): 262-305, 1971.

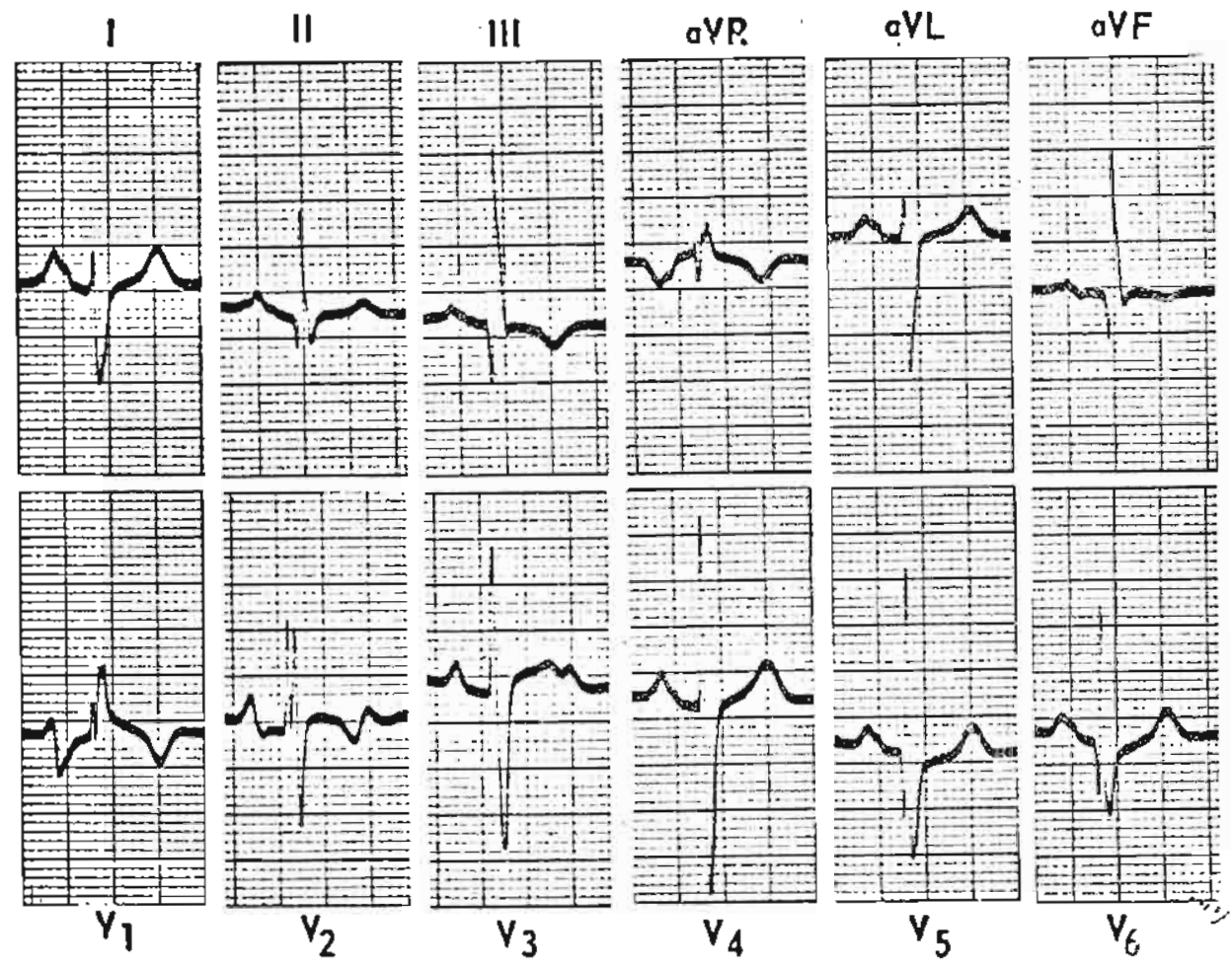

Fig. 5. Caso N 10: Electrocardiograma, 4,X.67. Crecimiento evidente de aurícula izquierda con algunos signos de crecimiento auricular derecho cuncomitanie. Bloqkeo de rama jerəcia (0.10) con eje de QRS en + 120". El compiejo ventricular puede indicar: crecimiento biventricular o bloqueo de rama derecha con hemibloqueo posterior izquierdo. Las ondas $Q$ profundas en $V_{5}$ y $V_{B}$ pueden eslat en relación con hiperlrofia sepial.

QRS en el plano fronterl se encontró ampliamente distribuida en los cuatro cuadrantes, ubicándose en solamente 7 pacientes, en posición normali en un paciente (No 6), el eje de QRS no pudo ser determinado.

El diagnóstico electrocardiográfico de crecimiento ventricular se estableció en 8 casos, de los cuales 7 presentaron hipertrofia ventricular izquierda $\mathrm{y}$ uno hipertrofic biventricular, no se encontró ningún caso de hipertrofia aislada del ventrículo derecho. En 10 pacientes se ob- servaron alteraciones de la onda $\mathrm{P}$ relacionados a crecimiento auricular izquierdo, en cambio solamente se encontró un caso de crecimiento auricular derecho; el crecimiento biauricular se registró en 5 pacienies. El criterio para el diagnóstivo electrocardiográfico fue el recomendado por Massie y Walsh (93), como ya se mencionó anteriorments. Es también im. portante notar, que en 5 pacientes se observaron alteraciones del complejo QRS, sugestivas de necrosis miocárdica, (Casos Nros. 6, 7, 13, 14 y 17), pero, como 
Batrilana G. C. A. Estudio Clínico de Enlermadad Miocárdica Primaria (Cardiomiopatía). Observaciones en 26 casos. An. Med. Univ. N. M. S. M. 54 (3): 262-305, 1971.

se verá más adelante, no se relacionaron en ninguno de ellos a infarto del miocardio. Fue dable observar también ondas $Q$ profundos en derivaciones $V_{5} Y V_{B}$. En 5 casos (Nros. 6, 9, 14, 19, 23), se detectaron imágenes electrocardiográficas ines. pecíficas de alteración miocárdica del ventrículo izquierdo. El bajo voltaje de los complejos QRS selectivo al plano frontal fue una alteración frecuente ya que pudo ser observada en 15 pacientes (Casos Nros. 3, 4, 6, 7, 8, 12, 14, 16, 17. $19,20,21,23,34,26)$. Solamente se encontró un caso que, aparte de una taquicordia sinusal, no presentó alteraciones morfológicas definidas, salvo ligeros empastamientos y melladuras del complejo QRS en $D_{11}$ y $V_{6}$, siendo la duración del complejo de 0.08 , estos hollazgos hom sido $\sin$ embargo atribuidos por algunos a

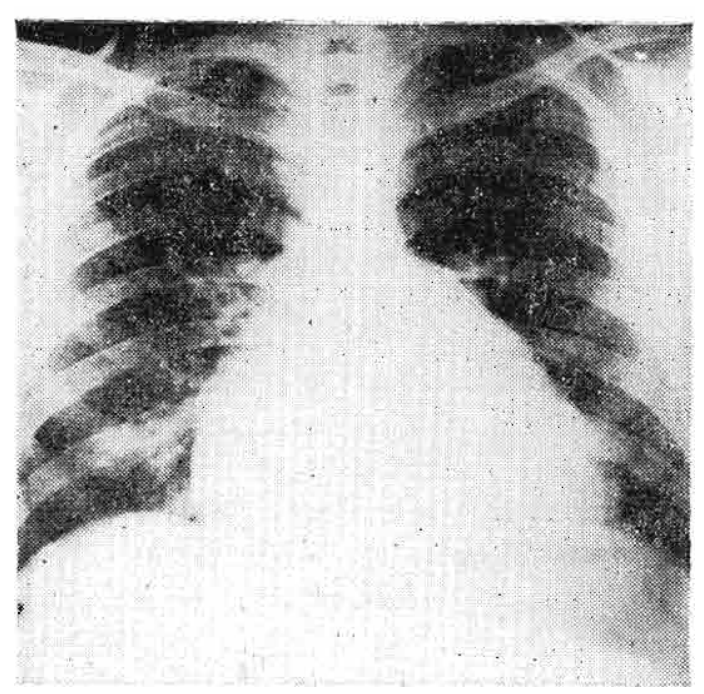

Fig. 6. Caso No 10: Telerradiografía de corazón, 6.X.67. Se abserva aumento de la silueta cardíaca en lodas sus dimensiones. fibrosis miocćrdica incipiente (89). Algunos registros fonocardiográficos y del apexcardiograma se han ílustrado en las figuras 24 y 25.

Estudio radiológico: En el examen fluoroscópico practicado en 17 pacientes, se encontró que la dinámica cardíaca estaba disminuida en 14 casos, en 2 era de carccteres normales, y en un caso, el No 9 fue indefinible por existir un derrame pleural bilateral que impedía la visualización de los bordes del corazón. Sobre 26 pacientes con telerradiografías del corazón, 18 casos presentaron cardiomegalia global (69\%), 2 casos tenían crecimiento de aurícula izquierda y ventrículo izquierdo (7.6\%), 5 casos solamente crecimiento del ventrículo izquierdo (18\%), no habiéndose podido detectar ningún caso con crecimiento exclusivo de las cavidades derechas. Es importante señalar la existencia de un caso, el No 21, que cursó sin agrandamiento cardíaco y que aparece ilustrado en las figs. No $15,16,17$ Y 18.

Cateterismo cardíaco: Los resultados de este examen permiten apreciar los hallazgos que van, desde lo esencialmente normal (caso No 1) hasta grados definidos de alteración hemodinámica, caracterizados sobre tedo por elevación de la presión diastólico en el ventrículo derecho $\mathrm{y}$ de la presión media de la aurícula derecha en los Casos Nros. 10 y 26, presentando también uno de estos últimos, No 10 , una elevación significativa de la presión capilar pulmonar; estos dos últimos casos mostraron un descenso del débito car- 
BATTILANA G., C. A. Estudio Cínico de Enfermadad Miocárdica Primaria (Cardiomiopatía). Observaciones on 26 casos. An. Med. Univ. N. M. S. M. 54 (3): 262-305, 1971.

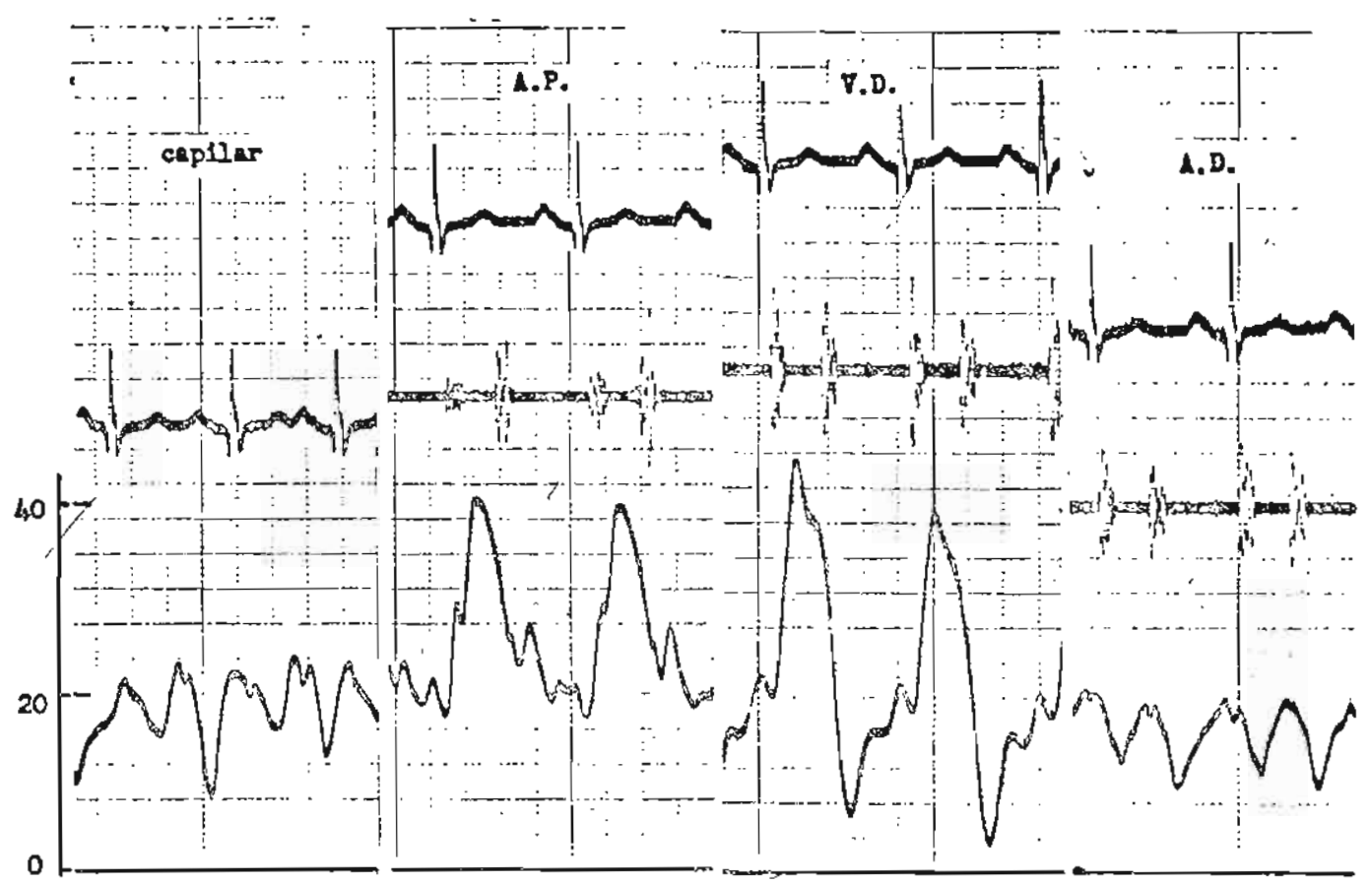

Fig. 7. Caso No 10: Registros lensionales dusante el cateterismo cardiaco de cavidades derechas, 4.X,67. Los curvas de aurícula derecha y "capilar" (Aurícula izquierda) fresentan una elevación lensional moderada $y$ una exageración de sus ondas negativas, sohre todo la " $y$ ". Existe una ligera elevación de la presión sistólica on la arteria pulmonar y el ventricu. lo derecho. La curva del ventrículo derecho muestra una importante elevación de la presión diastólica (dip y plateau), la onda " $a$ " también está elevada. El tonocardiograma exhibe un desdoblamiento constante del $2^{9}$ ruido. Las curvas de presión son compalibles con pérdida de la distensibilidad en ambos ventrículos.

díaço. El caso No 15 se caracterizó sobre todo por unc hipertensión pulmonar. Una demostración gráfica de alteraciones hemodinámicas puede verse en la figura No 7 correspondiente al caso No 10 , en el cual se ilustron curvas de presión con las características "caída y meseta" en el ventrículo derecho, $y$ ondas negativas en los trazos de aurícula derecha y capilar, anormalidades que sugieren un trastorno restrictivo.

Resultados de la anatomía patológi- ca: Del grupo de 26 pacientes en estudio fallecieron 14, realizándose la necropsia en todos ellos, pero, por limitaciones en el trabajo cotidiano, el estudio histológico se circunscribió al corazón. Los resultados individuales figuran en los resúmenes de las historias clinicas correspondientes.

De las 14 necropsias llevadas $a$ cabo figuran datos relativos al aspecto macroscópico del corczón en 10 casos, en cambio el estudio histológico fue realizado en todos. Macroscópicamente fue frecuente el hallazgo de engrosamiento de la pared 
BATTLfFiva G., C. A. Esludio Clinico de Enlermedad Miocórdica Primaria (Cardiomiopalia). Observaciones en 26 casos. An. Med. Univ. N. M. S. M. 54 (3): 262.305, 1971.

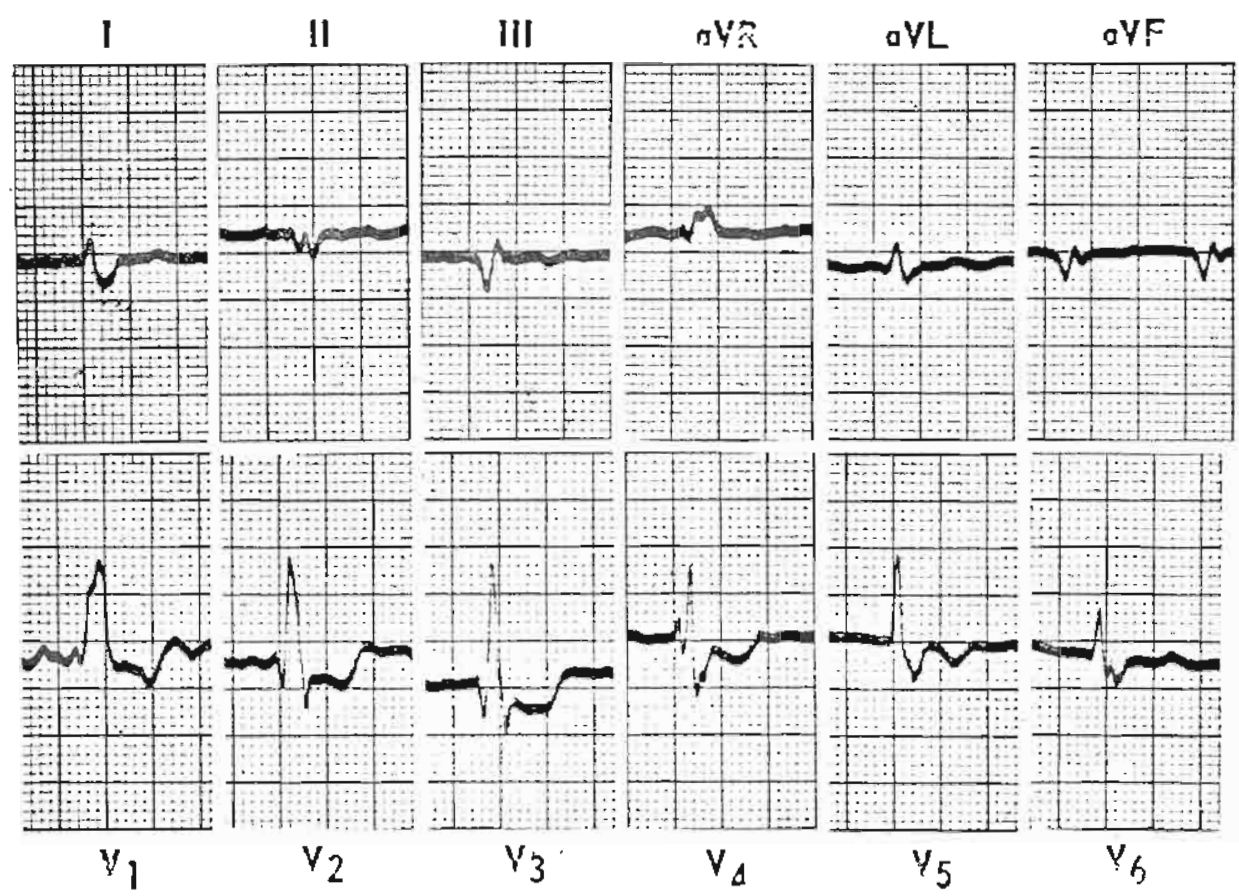

Fig. 8. Caso Ne 17: Electrocardiagrama. 3.VII.69. Fibrilación auricular. Bajo voltaje en de. rivaciones de los miembros. Bloquea de rama derecha (QRS 0,14 ) con eje de QRS en $-120^{\circ}$, complejes ventriculares en $W$ en II $y$ aVF, Qr en aVF, las dellexiones negativas iniciales son anchas y empastadas en eslas derivaciones. Los cambios de ST-T aparentan sel de tino secundario. Dichnóstico: bloqueo de rama derecha, necrosis antigua de pared inferior.

ventricular izquierda, en proporciones variables, así como también la presencia de dilatación de las cavidades; en 2 casos, Nros. 3 y 14 , se encontró trombosis mural, en otros dos pacientes Nros. 7 y 26 , se pudo apreciar la presencia de placas nacaradas en el endocardio del ventrículo izquierdo. Es interesante el caso No 21 por la ausencia de patología al examen moctoscópico del corazón.

En el estudio histológico de los 14 casos autopsiados se enconiraron hallazgos que sorprendieron por su repetida observación, a pesar de que correspondian a casos que clínicamente no fueron seme- jantes, estas alteraciones correspondieIon a:

Lisis muscular, depósitos de material eosinófilo, edema, degeneración gronular del sarcoplasmo, hialinización, pérdida de las estriaciones transversales de las miofibrillas, núcleos grandes y de aspecto bizarro, hipercromatismo, cromatina vesiculosa.

De todos estos hallazgos los más constantes fueron las alteraciones nucleares y la lisis muscular, habiéndose podido apreciar en esta última diferentes gradaciones que van desde la contracción del sarcoplasma y su separación del sar- 
BATTILANA G., C. A. Esludio Cinico de Enfermeóad Miocárdica Primana (Cardiomiopalia). Observaciones en 26 coscs. An. Med. Univ. N. M. S. M. 54 (3): 262.305, 1971.

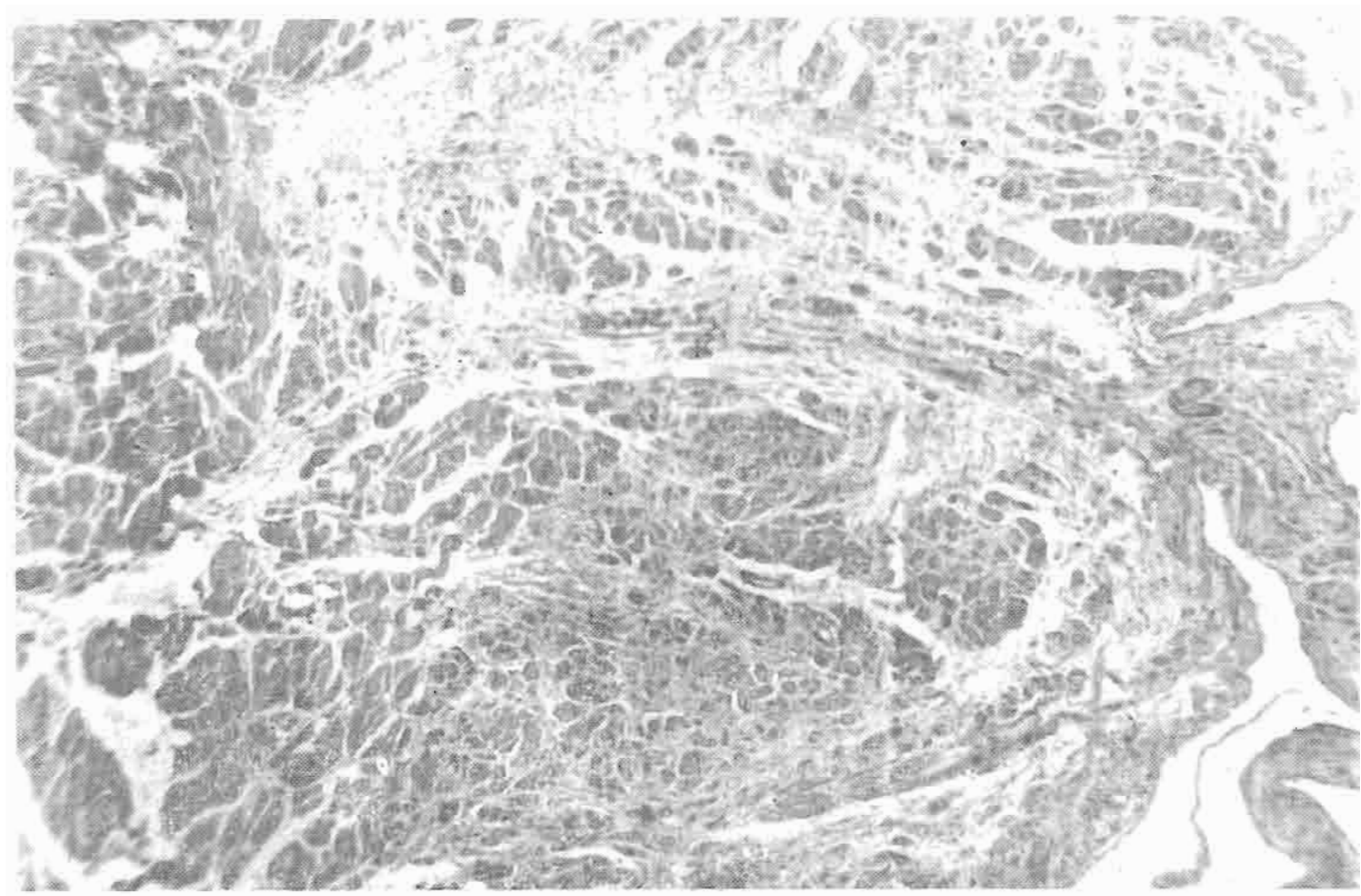

Fiq. 9. Caso N" 20: Autopsia N" 2066 (Hosp. 2 de Mayo). Vis:a panorámica de un corte de miocardio a nivel subendocárdico, mosirando lesiones más severas gue las ulusirados anteriomente. Se puede apreciar extensas zonas de miocilolisis. que permilen observar un amplio intersticio (it.E. X35).

colema, la desaparición del sarcoplasma con persistencia del sarcolema, llegando por último a la desaparición completa de la fibra.

Es importante hacer notar que con la sola excepción de los casos Nros. 4 y 26, no fue posible demostrar fibrosis miocárdica difusa o zonal, a pesar de haberse utilizado coloraciones específicas. La presencia de inflamación tampoco fue un elemento importante, pues sólo en algunos casos se la encontró en forma mínima. El estudio histológico de los va. sos coronarios fue negativo o muy discre. ta ateroesclerosis. En el caso No 17. de 64 años de edad, se halló, aparte de las lesiones anteriormente descritas y comunes a muchos casos, una zona pequena de infario agudo del miocardio. El caso $\mathrm{N}^{0} 21$ que aparentemente carecía de alieraciones al examen macroscópico, presentó las lesiones musculares ya descritas.

De la revisión bibliográfica $(58,73$, 77. 94) es posible determinar que una cardiomiopatía se hace manifiesta clínicamente en la década de los 40 a 50 años en la mayoría de casos, es importante 
BatTilanA G., C. A. Esludio Clínico de Enfermedad Miocárdica Primaria (Cardioniopalía). Observaciones en 26 casos. An. Med. Wni\%. N. M. S. M. 54 (3): 262-305, 1971.

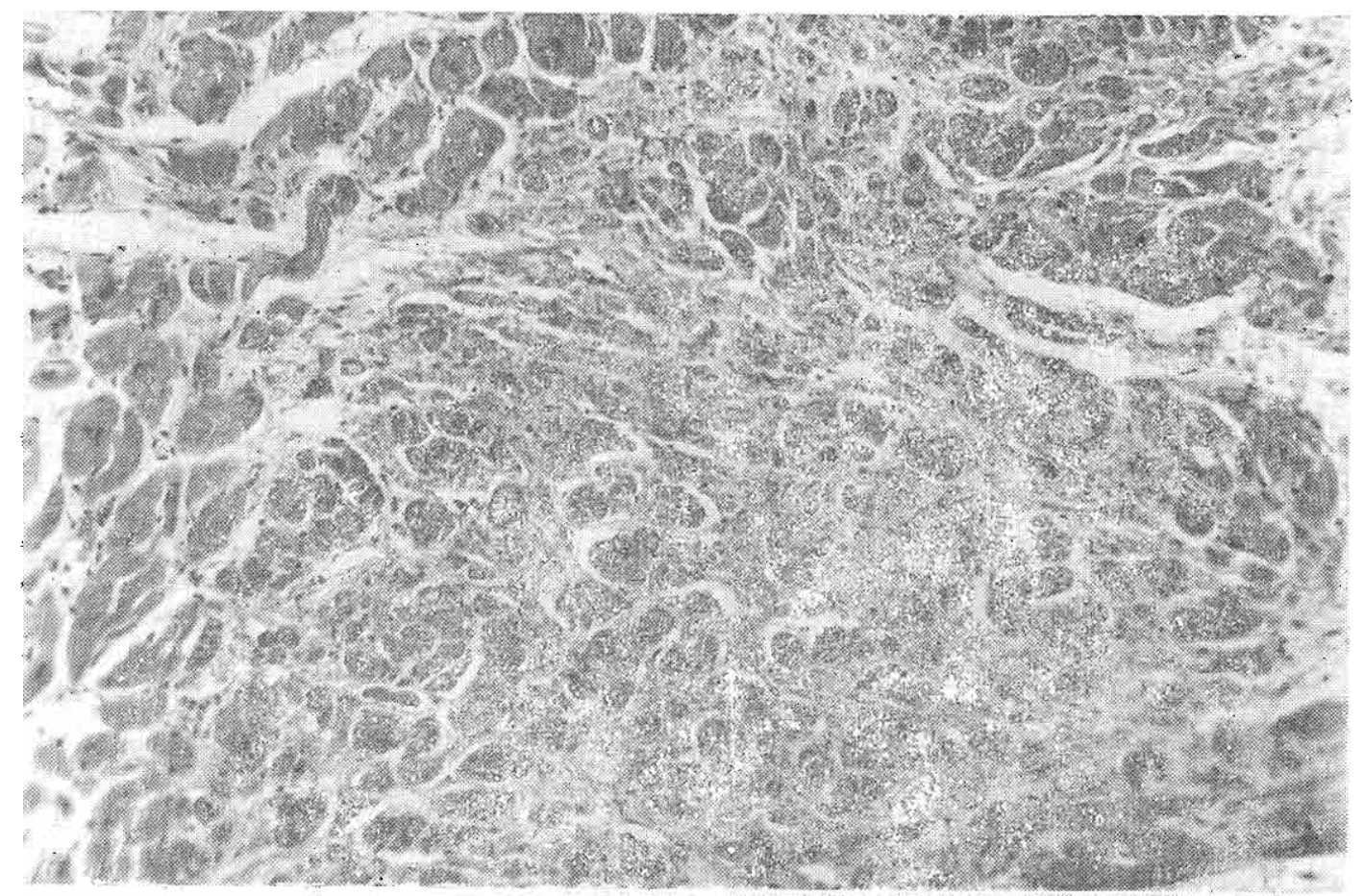

Fig. 10. Caso No 20: Autopsia $N^{0} 2066$ (Hosp. 2 de Mayo). A mayor aumento se puede apreciar acentuado daño miocárdico con miotibrillas anucleadas, por degeneración de ésle, en otras se observa hipercromatismo. Nótese el amplio espacio intersticial pero sin neolormación conjuntrva (H.E. X100).

hacer notar que el reconocimiento clínico de este síndrome es difícil en las edades extremas, sobre todo en la edad avanzada, en la cual la diferenciación con la cardiopatiơ ateroesclerótica parece ser extremadamente dificil en el terreno clínico, pues incluso las imágenes de necrosis características en el trazo electrocardiográfico de la cardiopatía isquémica, pueden también observarse en las car. diomiopatías $(77,92)$. En el otro extremo de la historia natural estarian los menores de 20 años, pacientes en los que un distingo con una afección miocárdica in- flamatoria es también difícil. En el grupo estudiado por nosotros, la edad promedio de aparición de los síntomas de 41.8 años guarda relación con lo recogido en la literalura, tres de nuestros pacientes fueron menores de 20 años (casos Nros. 3. 6 y 23), cuando fueron estudiados, lo que no llama la atención pues la cardiomio. patía puede ser observada incluso en niños $(16,75)$. Nuestros cosos de pacientes jóvenes se coracterizaron por un tiempo de evolución relativamente corto ya que ninguno de ellos vivió más de un año desde que se instalaron los síntomas. 
BAtTllana G., C. A. Estudio Clínico de Enfermedad Miocárdica Primaria (Cardiomiopalía). Observaciones en 26 casos. An. Med. Univ. N. M. S. M. 54 (3): 262-305, 1971.

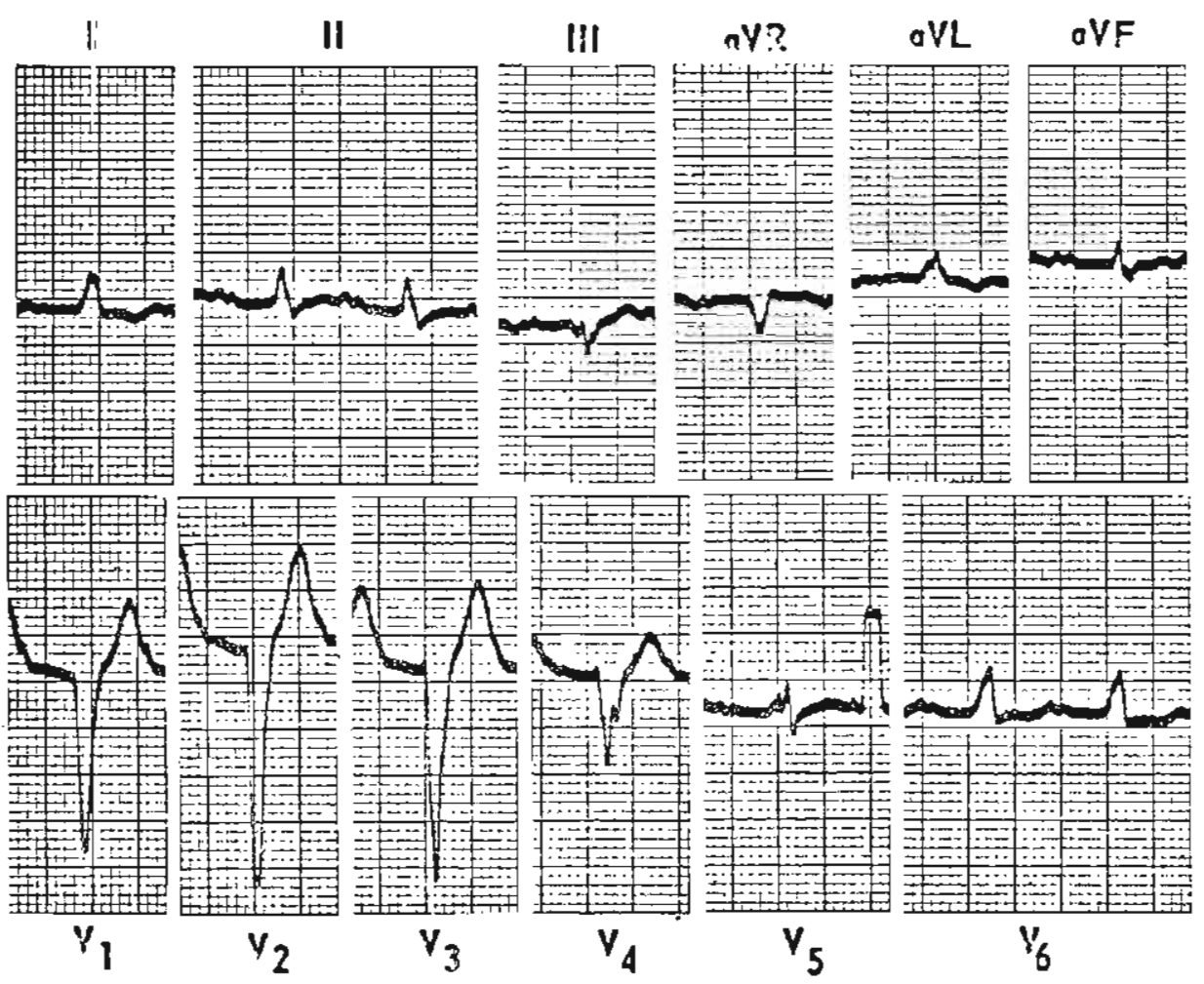

Fig. 11. Caso No 21: Electrocardiograma, 7.1.69. Ritmo sinusal. Primer zraco de bloqueo A-V (PR 0.26). Alteración de auricula izquierda. Bajo voltaje en derivaciones de los miembros. Bloqueo de Iama izquierda (QRS 0.11).

es importante señalai que estos tres casos tuvieron estudio anatomopatológico confirmatorio de cardiomiopatía. Dos pacientes fueron mayores de 60 años, casos Nros. 9 y 17 , en los que también la cardiomiopatía fue confirmada histológicamente; en uno de estos casos, el No 9 . se sospechó, en vida, que se trataba de una amiloidosis primaria, habiendo sido su evolución relativamente rápida; el otro paciente, Caso No 17, presentó algunas características que indicaban una cardiopatía ateroesclerótica, pero la larga evolución clínica fue lo que orientó el diagnóstico hacia una cardiomiopatía.
Ya se ha mencionado que el grupo estudiado fue predominantemente de hombres, características que no tendrían valor por la forma como fueron recogidos los casos, pero estudios procedentes de centros en los cuales la población hospitalaria es balanceada para ambos sexos, también demuestran una predominancia de la cardiomiopatía en el sexo masculino $(18,26,73,94)$, dándose razones como: alcoholismo, trabajo físico más intenso, exposición a noxas ambientales, etc. factores que alectan más a los hombres $(26,73)$. La literatura sobre cardio. miopatías menciona una alta incidencia 


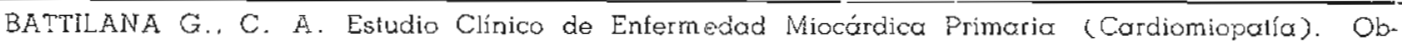
servaciones en 26 casos. An. Med. Univ. N. M. S. M. 54 (3): 262.305, 1971.

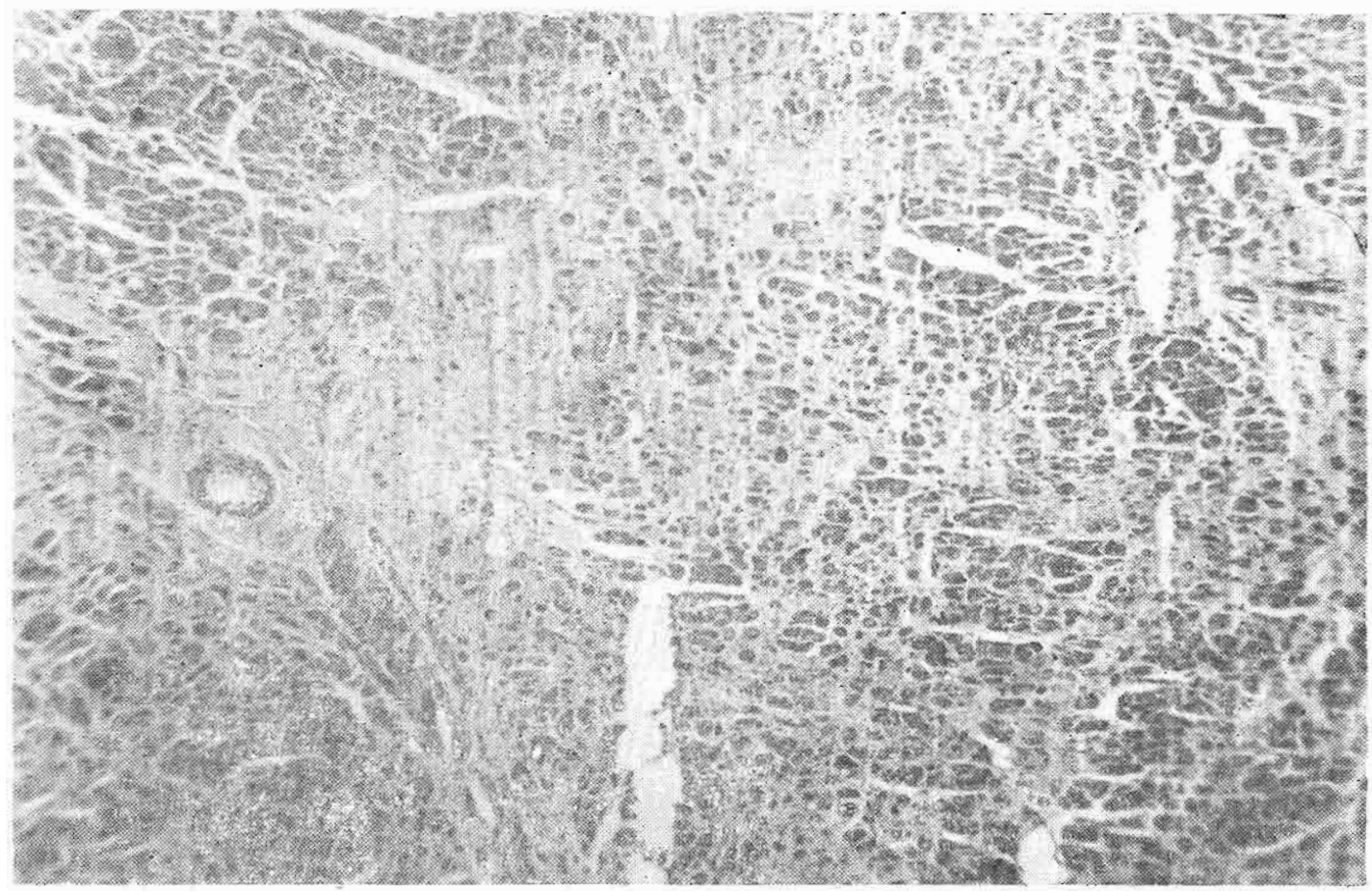

Fig. 12. Caso N? 21: Autopsia 2071 (Hosp. 2 de Mayo). Vista panoramica de uno sección del miocario mural. mostrando una amplia zona de miocitolisis, habiondo sido reemplazadas las miofibrillas por un lejido colágeno unilorme. Arierias de caracisres normales. 'H.E. X35).

de este padecimiento en la raza negra, no sólo en el continente africano propiamente dicho, sino también en otros lugares como, E.E.U.U., Brasil, Jamaica (73, $112,115,123)$, habiéndose tratado de explicar esta predominancia aparente en base a datos de tipo nutricional y ambiental (106, 118), que afectarian más a la raza negra. En el grupo estudiado por nosotros no se encontró ningún paciente de raza negra, estando éste formado casi en su totalidad por mestizos, con mayor - menor preponderancia de rasgos indigenas, la excepción la constituyó el caso No 18 que era de raza blanca. El predo- minio de mestizos no tiene ningún valor por ser éste el grupo predominante en nuestra población en general y hospitalaria, ounque podría aplicarse a ellos los argumentos que se han mencioncido a propósito de la raza negra en relación a la cardiomiopatía.

Se ha considerado de importancia el estado de la nutrición dado que el co. razón es un órgano que consume gran cantidad de oxigeno y utilizo múltiples substratos energéticos, por lo que se esperaría una repercusión sobre él en caso de déficit nutricional (106), incluso se ha descrito un sindrome de insuficiencia cor- 
BATTILANA G., C. A. Estudio Clínico de Enfermadał Miccórdica Prumaria (Cardiomiopatía). Ob. servaciones en 26 cosos. An. Med. Univ. N. M. S. M. 54 (3): 262-305, 1971.



Fig. 13. Caso 1N 21: Autopsia 2071 (Hosp. 2 de Mayo). A mayor aumento se puede apreciar mioibrillas aisladas rodeadas de colágeno untersticial, con núcleos hipercromálicos. En generat las miofbrillas están completamente atrótıcas y son puntiformes ( $H$. E. X100).

díaca en pacientes af́ricanos atribuido a malnutrición crónica (65). En años re cientes se ha dado importancia a la posible influencia del alcohol como causa de cardiomiopatía y se ha descrito específicamente una cardiomiopatía alcohólica $(2,22,24,27,50)$, que los autores han atribuido $a$ un efecto directo del olcohol sobre la fibra miocárdica, sin embargo existen opiniones que hacen notar la importancia de un déficit nutricional en estos pacientes que sería un factor condicionante para los efectos tóxicos del alcohol $(66,94)$, aunque sin referirse necesuriamente al beri-beri, que es un tipo de insuficiencia cardiaca hiperkinética, diferente del cuadro clínico de hiposistolia que se ve en la cardiomiopatía alcohólica. A la cardiopatía beribérica se puede llegar, según Evans (51), de dos maneras: ya sea por deficiente ingesta de $B_{1}$ por carencia nutricional, o por una dieta aparentemente normal pero con una carencia relativa de $B_{1}$ debido a su incrementada demanda para metabolizar el alcohol ingerido en exceso.

Una relación indirecta con el alcohol ha sido también mencionada en años recientes a propósito de la llamada cardiomiopatía de los bebedores de cerveza, en 
BATtLANA G., C. A. Esludio Clínico de Enfermedad Miocárdica Primaria (Cardiomiopatía). O'bservaciones en 26 casos. An. Med. Univ. N. M. S. M. 54 (3): 262-305, 1971.

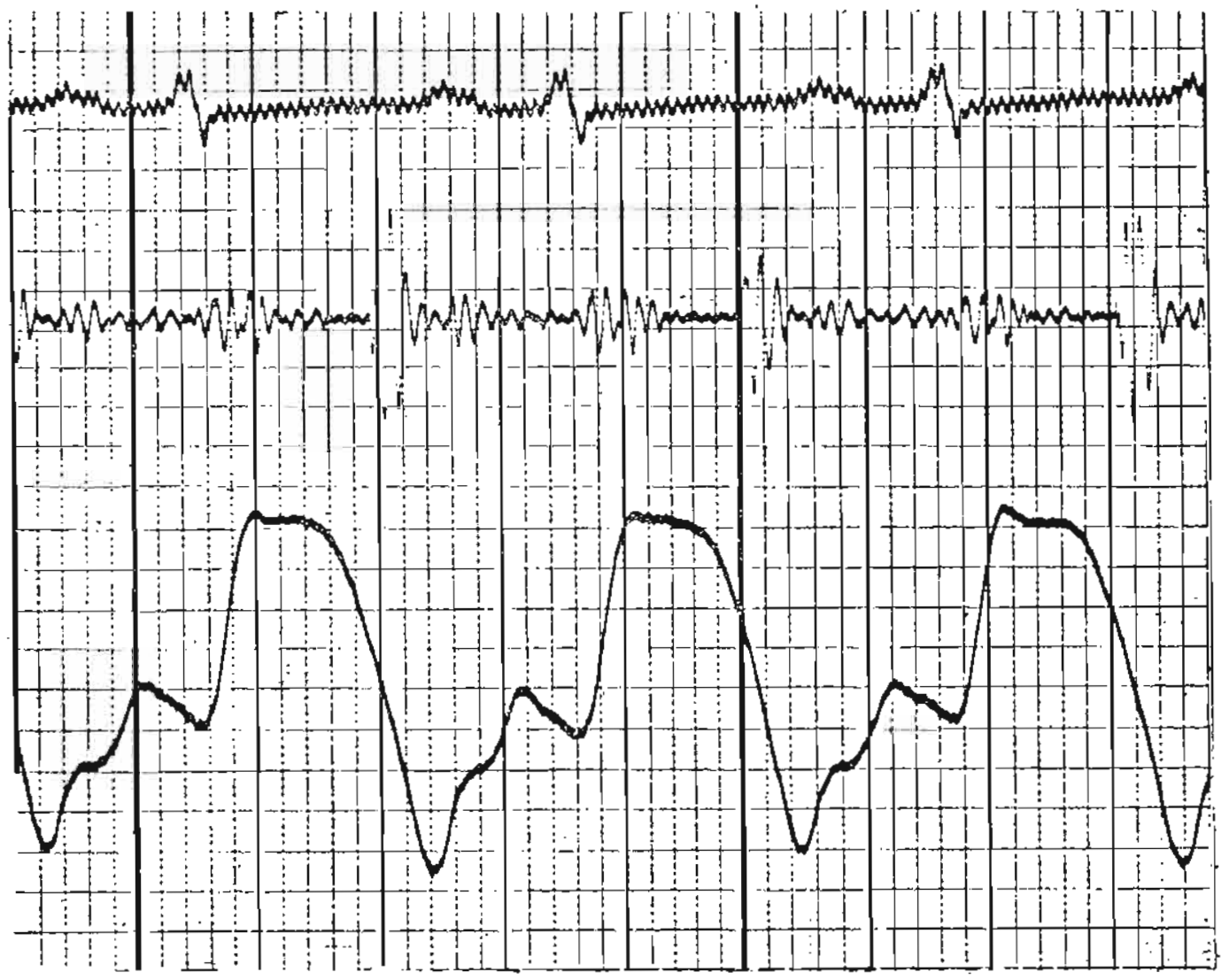

Fig. 14. Caso No 23: Registro de electrocardiograma, fonocardiograma (FSO) en un punto muy vecino al latido de la punta, el cual era el explorado con el dispositivo para obtener el apexcardiograma en decúbito láleral izquierdo. El apexcardiograma eslá muy alterado, la onda " $\alpha$ " muestra un punlo de origen elevado y una amplitud exagerada; el punto inmediato anlerior al inicio de la dellexión ventricular está también notablemente elevado, dando un indice telediastólico (Fishleder) muy anormal. El conjunto de alteraciones traduce una elevación de la presión diastólica ventricular izquierda.

Ios cuales, el efecto tóxico del cobalto, empleado como aditivo para estabilizar la espuma, necesitaría un substratum de un corazón con déficit nutritivo para poder actuar $(51,54)$, aunque, experimentalmente, el cobalto puede producir daño miocárdico sin mediar ningún factor nutricional ( 1,99$)$. Assimismo, desde el punto de vista experimental, se ha observado que el alcohol puede afectar la función cardíaca (21, 108, 140, 141). En nuestra casuística figuran 8 casos en los que el alcoholismo crónico fue una condición significativa y mantenida por un tiempo relativamente prolongado, es po. sible que estos casos representen ejem. 
Battilana G., C. A. Estudio Clinico de Enlermedad Miccádica Primatia (Cardiomiopalio). Observaciones en 26 casos. An. Med. Unv. N. M. S. M. 54 (3); 262.305, 1971.

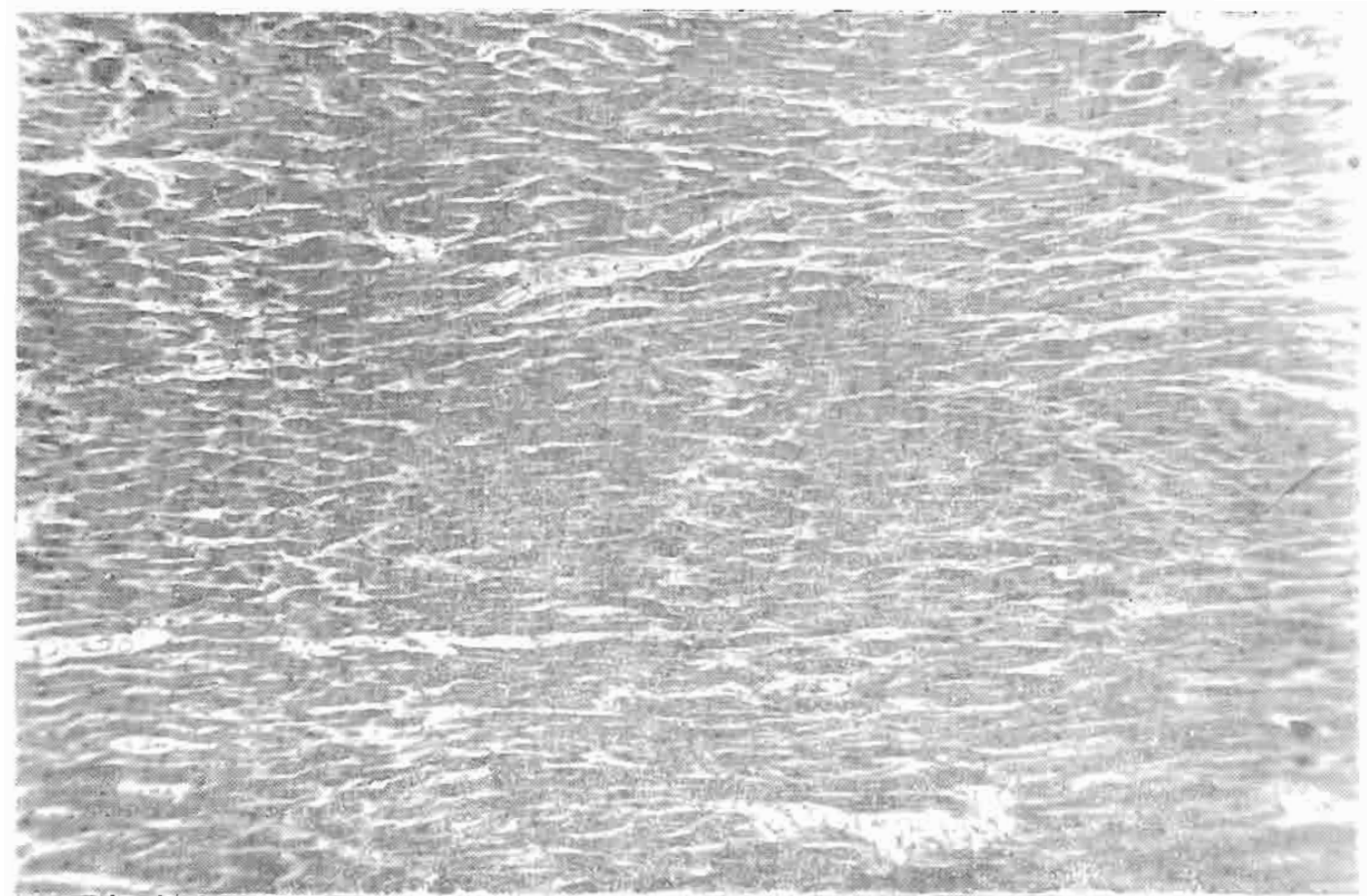

Fig. 15. Caso No 25: Autopsia 2086 (Hosp. 2 de Mayo). Visla panorámica del miocardio mostrando discrelo hiperaramatismo nuclear. No se observa maycr compromiso de las ibras musculares ni del intersicio (Hemaloritina-Eosina. X35 aumenlos).

plos de cardiomiopatía alcohólica; es necesatio hacer notar que ninguno de estos pacientes tuvo signos de déficit vitaminico.

La literatura pertinente menciona en forma repetida que los pacientes con cardiomiopatía presentan una sintomatolc. gía relacionada principalmente a insuficiencia cardíaca, lo cual no llama la atención pues la enfermedad es fundamentalmente miocárdica.

Las arritmias cardiacas se manifiestom también con relativa frecuencia, siendo las palpitaciones la expresión sinto. mática más relerida de ellas, aunque a veces es dificil distinguir en qué proporvión los trastornos del ritmo son causados por la enfermedad miocárdica propiamente dicha o por la digita! (77). Los sintomas debidos a embolismo son muy variados, dependiendo del territorio comprometido, siendo el origen de los émbolos las lesiones endocárdicas complicadas con trombosis mural, o la trombosis venosa, profunda en los pacientes con insuficiencia cardíaca congestiva (77): la frecuencia de los fenómenos embólicos varía en las diferentes series revisadas (11, 59, 73, 77), variaciones que han sido atribuidas al material utilizado, con- 
BATTilaNa G., C. A. Esludio Clínico de Entermeagd Miccárdica Primaria (Cardiomiopatía). Oo. servaciones on 26 casos. An. Med. Univ. N. M. S. M. 54 (3): 262.305. 1971.

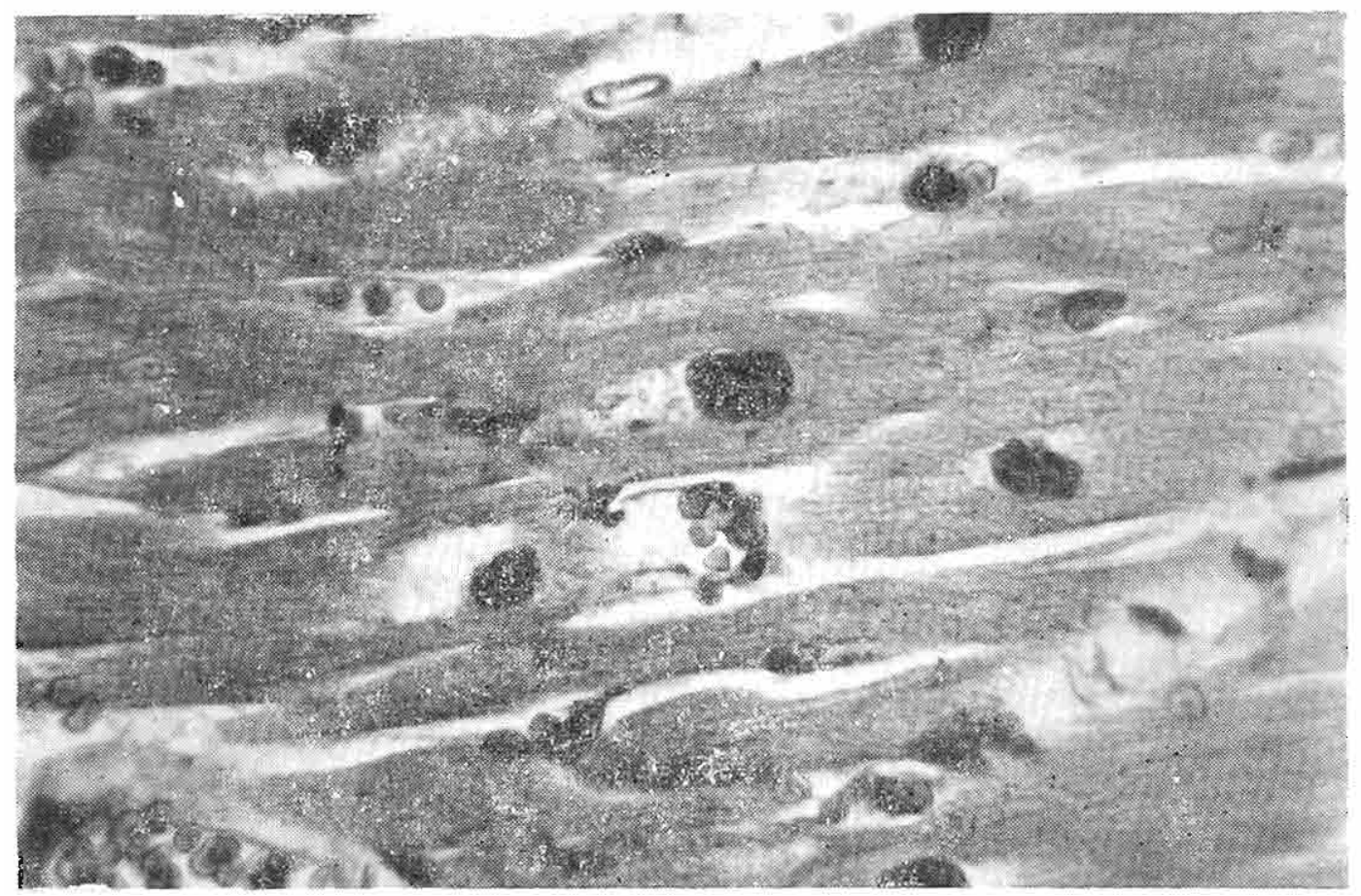

Fig. le Caso No 25: Autopsia 2086 (tionp. 2 de Mayo). A mayor aumonlo se aprecia hi. percromansmo nuciear $\gamma$ descoparición de las eslriaciones transversales de las libras muscula. res en la zona perinuclear (i.E. X400 aumen!os).

siderando que los pacientes en una etapa más avanzada de la enfermedad tendrían mayor predisposición a embolismo (77). Nuestras observaciones guardan relación con los comentarios anteriores, ya que, como se observa en los cuadros Nros. 4, 4a y 5, la sintomatología predominante fue aquella relacionada con la insuficiencia cardíaca, destacándose que solamente 4 pacientes presentaron un cuadro de edema agudo del pulmón; sólo un paciente cursó sin manifestaciones de insuficiencia cardíaca, presentándose la enfermedad con embolismo cerebral. En nuestra revisión figuran también va- rios casos con dolor torácico, pudiendo haber tenido relación con episodios de embolismos pulmonares, aunque en el caso $N ! 17$, la descripción sugería más bien insuficiencia coronaria, siendo, incluso, el electrocardiograma compatible con esta posibilidad, pero la necropsia descarló la presencia de cicatrices miocárdicas extensas, aunque pudo demostrorse un pequeño intarto agudo.

Desde el punto de vista clínico se pudo diagnosticar fenómenos embólicos en cuatro de nuestros pacientes, siendo en tres de ellos una complicación en el curso de un cuadro ya establecido, sola- 
BATrilaNA $Q_{.}$C. A. Estudio Clínico de Enfermodad Miocárdica Primaria (Cardiomiopatía). Observaciones en 26 cases. An. Med. Univ. N. M. S. M. 54 (3): 262-305, 1971.

mente en un caso, No 22, como ya se ho manifestado, el embolismo cerebral fue la manifestación predominante de la enfermedad; el porcentaje de fenómenos embólicos en nuestra serie correspondić a $15.4 \%$, que no se diferencia mayormente de lo encontrado en otras casuísticas más numerosas $(21,58,73,77,94)$.

Cuando los pacientes fueron examinados muchos de ellos estuvieron en ortopnea, pero el aspecto general, en lo que respecta a nutrición, era satisfactorio; solamente el caso No 4 , cursó con unx marcada ascitis y caquexia, aspecto que simulaba una pericarditis constrictiva. En lo que respecta al aparato circulatorio, los hallazgos son también parecidos a los observados por otros cutores $(13,21,45$, $58,67,73,77,94)$, habiendo también nosotros encontrado algunos casos con pre. sión diastólica ligeramente elevada, y diferencial corta, abservación ya realizada hace muchos años (88), y que ha sido interpretada como una elevación de la re. sistencia arteriolar periférica, en la fase de insuficiencia cardíaca, (88). En lo que respecta a la circulación venosa sis. témica, se consignan observaciones en solamente 16 de nuestros casos, indicativas de ingurgitación yugular, desafortunodamente no se mencionan datos de tipo dinámico, que han sido observados y registrados gráficamente por otros autores $(73,94)$, otorgándoles importancia diagnóstica, aunque también se describe que la exageración de las ondas " $x$ " e " $\mathrm{y}$ ", o " $\mathrm{y}$ ", pueden también observarse en la pericarditis constrictiva (2I, 59), siendo en ambos casos una manifestación de pérdida de la distensibilidad miocórdica; también se ha mencionado que las ondas " $a$ " $\mathrm{y}$ " $\mathrm{v}$ " pueden estar prominentes cuando existe hipertensión pulmonar o insuficiencia tricuspidea, respectivamente (146).

Respecto a los ruidos cardíacos, no se encontró una disminución constante de la intensidad de ellos como pudiera esperarse en una enfermedad predominantemente miocárdica, pues hubo una proporción semejante con aquellos en los cuáles tuvieron una intensidad normal; por otro lado. las características de los ruidos fundamentales no permiten la discriminación de una cardiomiopatía con otro tipo de enfermedad cardíaca (76). Otros hallazgos auscultatorios, como son los soplos y ritmos de galope, han sido mencionados como muy importantes en el diagnóstico de las cardiomiopatías, (76). y ésta ha sido también nuestra experiencia, pues como ya se ha referido, hemos tenido 14 pacientes con ritmo de galope, sin embargo, a diferencia de otros estudios $(73,77,94)$, no hemos encontrado el galope auricular como un hallazgo importante, en cambio el galope ventricular sí fue de frecuente observación en concordancia con otros autores $(21,45$ 76), y mostró una tendencia a persistir aún alcanzada la compensación cardíaca. Es interesante cómo una enfermedad predominantemente miocárdica es capaz de mostrar soplos a veces intensos y con amplia irradiación, que pueden prestarse a confusión con enfermedades que preferentemente comprometen el endocardio, $y$ que han sido interpretados como expresión de dilatación cardíaca, o sea de tipo "funcional" (21, 46, 73), estos soplos son frecuentemente sistólicos y localizados en el área mitral preferentemente; 
qunque también pueden ser percibidos en el área pulmonar o tricuspidea, sin emborgo se consideraba que los soplos tricúspideos ocurren más bien en los casos avanzados de insuficiencia cardíaca (77). Los soplos sistólicos pueden indicar también un daño orgómico del aparato valvular mitral o tricúspideo, como ocurre en la endomiocardiofibrosis (123). Algunos soplos sistólicos tienden a disminuir o desaparecer contorme mejora la insuficiencia cardíaca y se reduce la cardiomegalia (73), comportamiento que ha sido destacado como un dato para diferenciar una cardiomiopatía de una cardiopatía reumática, en la cual los soplos más bien se intensificarian al restablecerse la eficiencia miocárdica (61), esta última observación ha sido también experiencia nuestra, pues, como se ha mencionado en los casos 1 y 22 , los soplos sis. tólicos, intensos en el primer examen. prácticamente desaparecieron con la compensación cardíaca, $\mathrm{Y}$, en otro caso, $N^{\circ}$ 24, el soplo pansistólico registrado fonocardiográficamente no se acompañó de lesión orgánica mitral a la necropsia. Otro mecanismo cara el soplo sistólico en el áreo mitral en las cardiomiopatías, es el relacionado $\propto$ la disfunción del músculo papilar, el cual estaría comprometido como parte de la enfermedad miocárdica (9l). También puede percibirse un soplo sistólico, principalmente en el borde external izquierdo, cuando el pro. ceso miocárdico díficulta el vaciamiento ventricular, situación que ocurre fundamentalmente en la estenosis muscular subaórtica hipertrófica, este soplo sistóli. co es de carácter eyectorio, rasposo y en forma de diamante, pudiendo in acompa- ñado de frémito que, como ya se ha mencioncdo, se ausculta de preferencia en el borde external izquierdo, sin irradiación característica, a veces es de alta frecuencia pudiendo confundirse con el de la insuficiencia mitral, sin embargo puede ser diferenciodo debido a que se altera en forma particular con varias maniobras clínicas, así como también con los fármacos inotrópicos $(18,19,68)$.

Los autores han mencionado también, aunque con menor frecuencia, que los pacientes con cardiomiopatía pueden tener soplos diastólicos cortos, con las características de rodamiento $(77,116)$, los cuales, aisladamente, o asociados a soplos sistólicos mitrales, pueden plantear el diagnóstico de una cardiopatía reumática operable, $(87,120)$, e incluso se han descrito casos que fueron intervenidos quirúrgicamente, $(73,84,127)$. Otro elemento también importante es la diferenciación, a veces difícil, entre un galope ventricular y un rodamiento corto, incluso con el registro fonocardiográlico (116).

En cuanto a los exámenes de laboratorio son dignos de mención los resultados negativos en relación a la enfermedod de Chagas, pues, en los 10 pacientes en quienes se realizaron las pruebas correspondientes los hallazgos fueron negativos, confirmando la opinión ya mencionada en la introducción del presente trabajo, de que la enfermedad de Chagas, no es una etiología importante de cardiomiopatía, por lo menos en el área de Lima, incluso si se acepto que la población hospitalaria de Lima estó formada, en una buena proporción, por sujetos de origen $y$ procedencia provinciana, nues- 
BATTILANA G., C. A. Esludio Cínico de Enferm sdax Miccárdica Primaria (Cardiomiopaía). Observaciones en 26 cosos. An. Med. Univ. N. M. S. M. 54 (3): 262.305, 1971.

tros casos analizados en este respecto en el cuadro No 2, muestran que solomente 4 pacientes procedion del sur del país; pudiera entonces especularse que es escaso el número de pacientes provenien. les de zonas con cierta prevalencia de enfermedad de Chagas, pero los estudios de Cornejo y col. (36), concluyen que, a pesar de existir infestación por triatómidos y positividad de las pruebas en los grupos humanos estudiados en el sur, la car. diopatía chagásica crónica no alcanza la importancio que ello tiene en otros paí. ses. En cuanto a los dos pacientes sos. pechosos de toxoplasmosis, casos Nros. 14 y 15, los valores de los títulos alcanzados no fueron clínicamente significativos y como no se realizaron conlroles posteriores no se pudo establecer un aumento progresivo del título, lo que sumado a la negatividad de la reacción de fijación de complemento le quita todo valor diognóstico. Ia toxoplasmosis que fi. gura en otras series con relativa frecuencia como agente etiológico de cardiomiopatía, $(8,132)$, no parecería tener mucha importancia como tal en nuestro medio.

Otros exámenes de laboratorio factibles de realizarse en paciente con cordiomiopatía pueden expresar hallazgos inespecíficos, for ejemplo en relación a compromiso hepático secundario. La fórmu. la leucocitaria no indicó alteraciones, como sería la eosinofilia en el caso de la enfermedad de Loeffler o endocarditis parietal fibroplástica (40). El laboratorio sí tendría valor en el diagnóstico de las cardiomiopatías secundarias, sobre todo a través de pruebors o biopsias, como sucede en las colagenopatías, amiloidosis $y$ otras $(76,131)$.
El electrocardiograma es un método auxiliar que, en opinión de Mattingly (98), ha contribuido significativamente en el estudio de las cardiomiopaías, esta contribución es fundamentalmente en el aspecto diagnóstico, ya que se ha dicho que prácticamente todos los casos de cardiomiopatía cursan con un electrocardicgrama anormal $(21,45)$, sin embargo, la revisión de series grandes permite ver que existe un número aunque intimo de casos con electrocardiograma normal $(73,94,119)$. Algunos estudios en pacientes con cardiomiopatías pretenden distinguir las formas obstructivas, congestivas y restrictivas, valiéndose del trazo electrocardiográfico (80), el cual mostraría: hipertrofia ventricular izquierda, bloqueo intraventricular y bajo voltcje, e hipertrofia ventricular derecha respectivamente; sin embargo estudios posteriores concluyen que no existe un patrón electrocordiográfico diagnóstico de a!guna forma de cardiomiopatía, pudiendo encontrarse múltiples tipos de anormalida des morfológicas y de trastomos del ritmo cardíaco $(45,73,92,116)$. Los autores citados hacen referencia a que frecuentemente la onda $\mathrm{P}$ es anormal en las cardiomiopatías, en forma de una deflexión ancha y mellada indicativa de crecimiento curicular izquierdo, o bloqueo intraauricular, en cambio las ondas P de crecimiento auricular derecho se ven con menos frecuencia. El complejo QRS puede presentar alteraciones en relación a hipertrofia ventricular, bloqueo intra-ventricular e incluso presentor imágenes de necrosis semejantes a las del infarto del miocardio. El eje eléctrico de QRS en el plano frontal se ha encontrado desviado 
B.ATIIANA G., C. A. Estudio Clínico de Enfermadad Miocárdica Primaria (Cardiomiopatía). Ob. servaciones en 26 casos. An. Med. Univ, N. M. S. M. 54 (3): 262-305, 1971.

con frecuencia hacio la izquierda y muy rara vez hacia la derecha, siendo esta última situación factible de ver en el compromiso miocárdico de la ataxia de Friedrich (63). La imagen de hipertrofia ventricular izquierda es también de frecuente observación, pero no es exclusiva de la cardiomiopatía obstructiva ya que ha sido encontrada también en la cardiomegalica idiopática $(46,92)$, este mismo patrón electrocardiográfico es, en ocasiones, difícil de distinguir de los grados ligeros de bloqueo de rama izquierda ( 91 , 113). La hipertrofia ventricular derecha es raro y su presencia se ha relacionado a la fibrosis endomiocárdica (92).

La conducción intraventricular mues. tra en las cardiomiopatías gran variedad de alteraciones, que van desde las mues. cars del complejo QRS sin aumento de la duración hasta los clásicos bloqueos de rama de! haz de His; en lo que respecta $a$ eslos últimos son más frecuentes los de la rama izquierda, aunque se ha mencionado también los llamados "bloqueos atípicos" $(91,113)$. La pre-excitación ventricular es de observación rarar en las cardiomiopatías y se ha observado preferentemente en la forma familiar de estas enfermedodss $(92,117,142)$. Es interesante que en una proporción de casos se ha registrado ondas $\mathrm{Q}$ anormales $(71,73,77$. $92,94,105$ ), como aquellas vistas en $\in 1$ infarto del miocardio, pero que, al estudio anatomopatológico las lesiones encontradas han sido extensas pero no debidas a isquemia. También se han observado ondas $Q$ profundas, pero sin las características de las observadas en necrosiśs miocárdica, en las derivaciones precordiales izquierdas de pacientes con cardio- miopatía obstructiva $(44,68,80)$. El segmento ST y la onda T se encuentran frecuentemente modificados ya sea en for. ma secundoria a imágenes de hipertrofia, bloqueo intraventricular, o en forma primaria con un QRS sin mayores aiteraciones salvo alguna reducción de su voltaje $(71,77,92,105)$.

Nuestros casos mostraron hallazgos morfológicos parecidos a aquellos encontrados en la literatura, (Tabla No 9), debemos $\sin$ embargo hacer notar que 4 de nuesiros 8 pacientes con bloqueo de rama izquierda tuvieron el eje de QRS hacia la derecha, asociación que ya ha sido ilustrada en algunos trabajos $(45,92)$, pero que no ha recibido el comentario suficiente, creemos que estos casos indicarían un compromiso de las 2 subdivi. siones da la rama izquierda, o de áreas miocárdicas dependientes de ellas, pero con mayor predominio de la subdivisión pósteroinferior. En forma semejante se interpretarían los dos casos de bloqueo de rama derecha con eje hacia la izquierdo y arriba, lo que expresaría un com. promiso concomitante de la subdivisión ánterosuperior de la rama izquierda del haz de His; el caso No 10, considerado como hipertrofia biventricular puede tam. bién tener una interpretación alternativa en forma de bloqueo de la rama derecha con bloqueo concomitante de la subdivisión pósteroinferior de la rama izquierda; estos últimos conceptos se han tomado de las recientes publicaciones de Rosenbaum y col. $(91,113)$. Los otros casos, Nros. 7 y 17, se analizaron considerando el desequilibrio de las fuerzas ocasionado por la necrosis miocárdica. También es importante hacer notar que los 7 casos 
BATTLANA G., C. A. Estudio Ciinico de Enfermedad Miccárdica Primaria (Cardiomicpalía). Observacionss en 26 casos. An. Med. Univ. N. M. S. M. 54 (3): 262-305, 1971.

que tuvieron hipertrofia ventricular izquierda en el electrocardiograma no presentaron en vida una causa hemodinámica demostrable para esta hipertrofia. El hallazgo bastante frecuente de 15 casos con bajo voltaje en derivaciones standard, sin que existan factores, como anosarca, al tiempo del registro del trazado, se explicaría por una orientación selectiva hacia atrás de las fuerzas ventriculares que se ha demostrado por estudios vectocardiográficos en pacientes con cardiomiopatía (72) y que se traduciría por una reducción del voltaje en el plano frontal pero con deflecciones precordiales dere. chas de buena amplitud.

El mecanismo cardíaco en las cardiomiopatícs es generalmente sinusal aunque frecuentemente se observan alteraciones del ritmo (72), sin embargo, para al gunos (92) la incidencia de arritmias es semejante a la encontrada en otras car. diopatías. Dye y col. (45) consideran igualmente que las arritmias no son frecuentes, aunque se acepta que pueden observarse preferentemente contracciones prematuras ventriculares y fibrilación auricular, hecho que también ha sido nues. ira experiencia.

Un elemento importante a considerar en este tópico es cuánto de estas arritmias es debido a la enfermedad miocárdica y cuánto a la digital (77). Los tras. tornos de la conducción aurículo-ventricular no son de frecuente observación en las cardiomiopatías ( 92 ), habiéndose registrado sólo bloqueos de primer grodo en algunos casos, sobre todo en la cardiomiopatía familiar; los hallazgos de Lira (90), difieren de lo anterior, pues en 3 casos de cardiopatía oscura encontró bloqueo arículo-ventricular en 2, siendo uno de ellos de grado avanzado.

Cabe mencionar que, dentro de la aceptada inespecificidad del electrocardiograma en las cardiomiopatías, se hace mención, sin embargo, a algunos portrones sugestivos de estas enfermedades como son: la combinación de crecimien. to de auricula derecha con signos de hiFertrofia ventricular izquierda (80), o también la existencia de crecimiento de aurícula derecha con el eje de QRS ha. cia la izquierda (80).

Desde nuestro punto de vista, y bct sados en nuestros casos así como de la revisión de los trazos publicados por otros autores, creemos que un patrón electrocardiográfico caracterizado por: bajo voltaje en derivaciones de los miem. bros, bloqueo intraventricular izquierdo con eje de QRS a la derecha en el plano frontal, es fuertemente sugerenie de una cordiomiopatía, como ya ha sido anteriormente mencionado (104). Descforlunadamente los hallazgos electrocardiográficos son muy variados y para algunos (92), por sí solos, no tendrían valor diagnóstico en las cardiomiopatías (98).

Finalmente, debe considerarse a la electrocardiografía ccmo un método diag. nóstico muy sensible, pues es capaz de detectar alteraciones aún en casos asintomáticos, por lo que se le ha utilizado como un método de despistaje en las car. diomiopatías, sobre todo y como se verá más adelante, en grupos familiares (142).

El estudio hemodinámico de las cardiomiopatías se realizó, inicialmente, como parte de la investigación clínica en estos casos, con la esperanza de encontrar algún comportomiento característico, 
BAfILANA G. C. A, Estudio Clínico de Enlern sdad Miocárdica Primaria (Cardiomopatía), Obscrvaciones en 26 casos. An. Med. Univ. N. M. S. M. 54 (3); 262-305, 1971

sin embargo, la observación de los hallazgos hemodinámicos en trabajos específicamenie orientados sobre este punto $(10,74,145)$, o como complemento de amplias revisiones integrales sobre car. diomiopaitas $(18,73,94)$, no permite concluir sobre un patrón hemodinámico caracierístico de estas enfermedades, pues los haliazgos indicativos de menor distensibilidad miocárdica y compromiso de la eficiencia miocárdica no son patrimonio de las enfermedades que afectan al miocardio, ya que hon sido también observadas en afecciones restrictivas del pericardio (49) y del endocardio (32), e incluso la diferenciación mencionada por Yu (145), de que la presión diastólica veniricular en las enfermedades miocárdicas no superará el tercio de la presión sistólica, no ha sido confirmada posteriormenie. Otro punto diferencial es el señalado por Wood (144), respecto a la mayor presión encontrada en la posición capilar (curícula izquierda) comparativamente con la registrada en la curícula derecha, que en la pericarditis constrictiva lienden a ser iquales. En conclusión. pues, los hallazgos hemodinámicos son, como se ha dicho, inespecíficos y comunes para enfermedades resirictivas del endocardio, miocardio y pericardio. A pesar de esto, el cateterismo cardíaco ha contribuico en las cardiomiocatias a una mejor comprensión de la fisiopciología de ellas, al permitir su diferenciación según Goodwin (67) en: cardiomiopatía congestiva, restrictiva y obstructiva. Los esiudios hemodinámicos sí parecen tener imporiancia diagnóstica en el caso de la cardiomiopatía obstructiva, pues en ella, por la localización del obstáculo hemodi. nómico, es posible oblener gradientes tensionales indicativas de obsirucción en el tracto de salida, tanto en el ventrículo izquierdo (19) como en el ventrículo de. recho $(68,122)$, es de noiar que estas gradientes lensionales a veces tienen que ser inducidas farmacológicamente (19). Nuestra casuística es muy limilada en es te respecto, habiendo oblenido resultados semejantes a los de otros autores, los casos Nros. 1 y 15, cuyas pre siones diastólicas en ventrículo derecho, estuvieron deniro de lo que indicaría ausencia de insuficiencia cardia ca, lo cuai hace dificil de explicar la presión sistólica pulmonar inusitadamente elevada en el caso No 15; también llama la quención los datos esencialmente normales del caso cateterizado después de haberse logrado una complela com. pensación cardíaca, situación ya descri. to en entemedades miocárdicas (145) pero en pacientes asintomálicos. Por último, se debe mencionar lambién, que estos procedimientos, que implican la intro ducción de sondas al corazón, son polencialmente riesgosos en pacientes con $\alpha$ vanzada insuficiencia cardícaca, por la fa cilidad con que pueden desencadenarse orritmias ventriculares.

La radiología es un método fundamental en el estudio de las cardiomiopatías ya que permite deteciar el crecimiento cordíaco, elemento importante en estas enfermedades, no sólo como un dato aislado sino muchas veces como una información evolutiva demostrando una cardiomegalia progresiva, hecho apreciable en algunos estudios epidemiológicos (112). Dadas las limitaciones del método no es posible establecer una imagen 
BATTILANA G., C. A. Estudio Clinico de Enfermadad Miocárdica Primaria (Cardiomiopalia). Observaciones en 26 casos. An. Med. Univ. N. M. S. M. 54 (3): 262-305, 1971.

radiológica característica de las cardio. miopatías, en razón a la gran movilidad anatómica de estas enfermedades, $\sin$ embargo, la revisión de las ilustraciones de casos de la llamada "hipertrofia idiopática del corazón" (47,87, 115, 139), parece mostrar un crecimiento selectivo del borde izquierdo que las diferencia de las cardiomiopatías con crecimiento difuso no hipertrófico, en las cuales se encuentra una imagen que desborda ambos lados de la sombra cardíaca prestándose a confusión con derrames pericárdicos, e incluso, a veces, no es posible concluir por la fluoroscopía, debiéndose recurrir a otros procedimientos como la angiocar. diografía. Nuestra casuística muestra una amplia gama de morfologías radiográficas en relación a crecimiento cardíaco, siendo la excepción el caso No 21 que mostró una imagen practicamente normal, pero con profunda alteración en el electrocardiograma y en la onatomía patológica. Como se ha dicho, en algunos casos fue difícil observar la silueta cardíaca por la presencia de derrames pleurales.

La angiocardiografía ha prestado una cuntribución importante en el estudio de las cardiomiopatías, no sólo en el diagnóstico de las formas obstructivas del tracto de salida ventricular sino también en el descarte del derrame pericárdico ya mencionado, así como en el diagnóstico de insuficiencia valvular $(17,73)$; pero su mayor aporte pareceria estar en el estudio morfológico y dinámico de la cavided ventricular izquierda, ya que se ha demostrado $(17,73,74)$ que es posible calcular el grosor de la pared libre y las características de contracción ventri- cular, lo cual permitiría señalar los casos con hipertrofia o dilatación, así como la existencia de patrones anormales de contracción. Otra contribución de este método sería a través de la arteriografía coronaria para el descarte de la arterioesclerosis coronaria en pacientes de edad avanzada con insuficiencia cardíaca de origen oscuro (97) y, por último, esta técnica también resulta útil para el diagnóstico de la pericarditis constrictiva y su diferenciación con una cardiomiopatía en un caso dado $(107,121)$.

Los métodos gráficos correlativos, que toman en cuenta fenómenos de tipo eléctrico sonoro y mecánico, son de importancia, pues la información que pro. porcionan con relación al ciclo cardíaco y sus características son bastante exactas si se les compara con las obienidas por el cateterismo cardíaco, aparle de que pueden repetirse varias veces y no implican peligro para el paciente, situación a considerar en el caso de una cardiomiopatía avanzada. Estos mélodos externos pueden informarnos acerca de la eficiencia de la contracción del ventrículo izquierdo, duración de la sístole ventricular, presión diastólica ventricular izquierda y otros datos, como se puede apreciar en diferentes trabajos al respecto $(94,135)$. Un ejemplo del valor de un registro externo está dado por la gráfica del pulso carotídeo en casos de esienosis muscular subaórtica hipertrófica, en la cual, característicamente, el ascenso rápido va seguido de una caída sistólica y de un segundo pico $(14,60)$.

En el caso No 23 el registro del pul. so carotídeo nos permitió observar una onda dicrótica exagerada, que estaría en 
BATTilanA G., C. A. Esiudio Clínico de Enlermadad Miocárdica Primaria (Cardiomiopatio). Observaciones en 26 casos. An. Med. Univ, N. M. S. M. 54 (3): 262-305, 1971.

relación con insuficiencia ventricular izquierda y como tal ha sido descrita en cardiomiopatías (52). Fig. No 25.

Otro ejemplo del valor de los registros externos está dado por las alteracio. nes del ápex-cardiograma producidas por la insuficiencia contráctil del ventriculo izquierdo, como se aprecia en el coso $\mathrm{N}^{\circ}$ 23, en el que el "índice telediastólico" de Fishleder (55) está sumamente aumentado, lo cual nos traduce una elevación de la presión diastólica final del ventrículo izquierdo. Los métodos externos como ei fonocardiograma, pueden dar información documentaria en relación a soplos o ritmos de galoce, pero su mayor importancia reside, como ya se ha referido, en su correlación con los otros fenómenos cardíacos.

En lo que respecta al diagnóstico de las cardiomiopctías, se ha mencionado que una situación favorecedora de su ha. llazgo coda vez mayor en los años recientes es la disponibilidad de métodos auxiliares eficientes, pero como también hemos comentado en párrafos anteriores, todos ellos tienen limitaciones y ninguno por sí solo permitiría al médico asegurar que un paciente sufre de una cardiomio. patía. El diagnóstico pues, debe aún descansar en una apreciación clínica con el debido respaldo de algunos métodos auxiliares, este diagnóstico es sin embargo todavía de descarte, debiendo sospecharse una cardiomiopatía frente a un caso de insuficiencia cardiaca que no corres. ponda a las etiologías de cardiopatía conocida, pero en algunas oportunidades es posible encontrarlas fortuitamente como casos de agrandamiento cardíaco de origen desconocido, como alteraciones electrocardiográficas importantes en el curso de exámenes rutinarios que incluso pueden no acompañarse de agrandamiento cardíaco o, finalmente, como episodios embólicos en pacientes hasta ese momento asintomálicos. Prácticamente todas estas consideraciones diagnósticas las hemos aplicacio en los casos estudiados por nosotros y que forman la casuística del presente trabajo, y en base a ello el diagnóstico fue, en lodos los que fallecieron, un hecho establecido antes del deceso.

El médico frente a un caso de insuficiencia cardíaca debe considerar inicialmente las etiologias más frecuentes de cardiopatía, pero ante un elemento discordante debe pensar en la cardiomiopapatía que, como hemos dicho, puede presentarse no solamente con manifestaciones cardíacas sino también en otros territorios. El diagnóstico es, pues, de tipo djferencial, situación que ha sido muy bien analizada por Fowler (60), para, en una segunda etapa, intentar una relación etiológica del cuadro con algún proceso específico, lo cual es todavía infructuoso en un buen número de casos. Un problema diagnóstico importante es el de los pa. cientes de edad avanzada en los cuales se sospecha una cardiomiopatía y en quienes debe descartarse en primer lugar una cardiopalía ateroesclerótica; este importante dilema, como ya se ha referido antes, lo tuvimos con dos pacientes, Nros. 9 y 17. Mattingly ha analizado este problema también (97), en el cual la angiogratía coronaria sería un método decisivo, aunque algunos autores (60) consideran que no tiene un valor práctico ha- 
BattilanA G., C. A. Estudio Clínico de Enfermedad Miocárdica Primaria (Cardiomiopatía). Observaciones en 26 casos. An. Med. Univ. N. M. S. M. 54 (3): 262-305, 1971.

cer un distingo diagnóstico en estas enfer. medades por la falta de un tratamiento específico.

Un aspecto importante del grupo es. tudiado en el presente trabajo, es la existencia de 3 pacientes hermanos (casos 4 , 20 y 21) en los cuales el diagnóstico de cardiomiopatía fue confirmado por la anatomía patológica, además, un tío materno que falleció en el Hospital Obrero tuvo una historia compatible con cardiomiopatía, asimismo, el deceso de la madre a los 46 años, de un episodio aparentemente embólico también hablaría en favor de una enfermedad miocárdica. La primera explicación para los 3 casos estudia dos sería una infección ocurrida en los primeros años de la vida de estos hermanos que se separaron en la primera infancia y cuya cardiopatía vino a manifestarse en la edad adulta, aproximadamente 30 años más tarde, lo cual sería una evolución inusitadamente larga para una secuela post-infecciosa; otro dato en Ielación a una etiología infecciosa supondría un problema de tipo endémico afectado a dos generaciones. Parece más factible la existencia de una etiología fa. miliar, que ha sido definida claramente en estudios sobre cardiomiopatías, no sólo del tipo difuso sino también del obstructivo $(18,20,30,41,83,102,134)$. Literatura revisada muestra que la sintomatología de los casos familiares es semejante a las de las formas comunes de cardiomiopatía: insuficiencia cardíaca congestiva, embolismo, arritmias y muerte súbita, que pueden aparecer aún en los primeros años de vida (134). La electrocardiografía se ha manifestado como un método sensible de diagnóstico, sobre to- do en casos asintomáticos (102), por lo que se le ha recomendado en el despista. je de grupos familiares con supuesta entermedad miocárdica (98); los hallazgos varían desde simples cambios de la onda $\mathrm{T}$ hasta imágenes bizarras de bloqueo intraventricular, vistas sobre todo en los zasos clínicamente manifiestos. El síndrome de Wolff-Parkinson y White, aunque infrecuente, sería algo peculiar de la 1orma familiar de cardiomiopatía (92, 117). La radiología se describe como importante fara la detección de los casos asintomáticos y en el despistaje de grupos familiares $(102,112)$. Finalmente la evolución tiende a ser corta, falleciendo en la tercera o cuarta década, siendo excepcional el caso reportado por Campbell y col. (30), de 66 años de adad. La forma del deceso es generalmente súbita (134).

Otra forma interesante de enfermedad miocárdica primario es la llamada cardiomiopatía post-partum, de la cual puede ser un ejemplo el caso No 22 de nuestro estudio, que se caracteriza por la aparición de insuficiencia cardíaca entre el último trimestre de gestación y la veinteava semana de puerperio (30, 136). sin embargo, la existencia de esta forma de cardiopatía como una entidad definida está todavía sujeta a debate, pues hay quienes creen que no se trate más que de una falla cardíaca secundaria a factores conocidos como: toxemia, embolia pulmonar, hemorragia, etc. $(12,130,136)$, no pudiendo descartarse la posibilidad de que se trate de una cardiomiopatía idiopática presente ya antes de la gestación que, por los cambios hemodinámicos propios de ella, adelantaría la aparición de 
BATTILANA G., C. A. Estudio Clínico de Enlermodad Miocardica Primario (Cardiomiopalia), Observaciones en 26 casos. An. Mel. Univ. N. M. S. M. 54 (3): 262-305, 1971.

las manifestaciones clínicas de esta en fermedad (23). La evalución de estos pacientes es incierta, viéndose complicada con episodios de tromboembolismo, bronconeumonía, pielonefritis aguda y arritmias, siendo la muerte súbita una complicación frecuente. Parece ser que las gestaciones subsecuentes al primer episodio de insuficiencia cardiaca pueden agravar el cuadro y en un número de ellas terminar en aborto o parto prematuro, sin embargo en algunos casos es posible no ver este desarrollo, y aun que no se presente un nuevo episodio de car. diomiopatía posi-partum (25, 136). La respuesta al tratamiento digitálico es bue no en la mayoría de casos, aunque la frecuencia de intoxicación es relativamente elevado debido a una susceptibilidad transitoria a esta droga, $(25,136)$, también el reposo prolongado en cama parece tener efectos beneficiosos, sobre todo en la reducción del tamaño del corazón (28), hecho que ya ha sido comentado anteriomente a propósito de la cardiomiopatía alcohólica (25). La mortalidad en las diferentes series es variable. habiéndose encontrado hasta el $60 \%$ en una de ellas (136), dependiendo ésta de factores diversos, como por ejemplo: complicaciones, gestaciones posteriores, respuestas al tratamiento y el estado de nutrición.

El grupo más numeroso de nuestra casuística es el formado por los pacientes que fueron calificados como casos de cordiomiopatía idiopática, predominio que también se aprecia en la mayoría de los trabajos sobre enfermedades del miocardio (21, 46, 58, 77, 85, 94). Este grupo, como se observa en el cuadro No
3 es bastante heterogéneo pues comprende a pacientes de diferentes edades con extremos de 13 a 64 años, evoluciones cortas con muerie en pocos meses, respuestas satisfactorias o mediocres al tratomiento, crecimiento cardíaco en todos ellos, y patrones electrocardiográficos variables en todos ellos: la causa de su hospitalización, o deceso, fue la insuficiencia cardiaca, manifestación que sería un común denominador para estos casos y lo que permitiría el diagnóstico, quedando los métodos auxiliares sólo como elemenios confirmatorios de la cardiopatía. La situación es, pues, poco satisfactoria, ya que un diagnóstico de cardiomiopalía idiopálica conlleva, al presente. una idea de ignorancia respecto al estado real del corozón en estos casos, e incluso la anatomía patológica que, en algunas situaciones, es de utilidad para certificar ciertos procesos miocárdicos, por ejemplo la amiloidosis, que en vida pueden presentarse con el síndrome de insuficiencia cordiaca, en muchas oportunidades sólo ofrece una imagen histológica inespecífica. En relación al problema de las formas idiopáticas, es pertinente relerimos a la llomada "miocarditis perniciosa" reactualizada por Saphir (84), en la cual el cuadro clínico de evolución relativamente corta podría confundirse. en un terreno puramente clínico, con casos de cardiomiopatía idiopática de rápida evolución, como fue nuestra experiencia en los casos Nros. 3.7 y 23 , que también fueron los más jóvenes. En es. to situación, si el cuadro histológico presentara signos de inflamación el diagnóstico indicaría una miocarditis, pero como la inflamación es un proceso que tiende 
BatTILANA G., C. A. Esludio Clínico de Entermedad Miocárdica Frimaria (Cardiomiopatía). Observaciones en 26 casos. An. Med. Univ. N. M. S. M. 54 (3): 262-305, 1971.

a desaparecer con el tiempo o transformarse en una alteración de tipo inespecífico y/o cicatricial, los pacientes observados en esta última elapo podrian ser catalogados como cardiomiopatía, quedando siempre la duda de si la supuesta forma idiopática es en realidod la conse. cuencia de un proceso infeccioso previo $(21,98)$; algunos autores han considerado la posibilidad de infecciones virales (21, 84). Un tipo de cardiomiopalía con características especiales es la endomiocardio-librosis, descrita principalmente a base de casos observados en el Arica Central $(33,34,40,112,123)$, pero que no es exclusiva de esta región ya que también se ha encontrado en otras áreas ( 6 . 37, 101, 123), pero con la particularidad de ser todas regiones tropicales o sub-tropicales (123). La nosografía de esta enfermedad se caracteriza por presentar, un cuadro clínico en relación a compro. miso ventricular izquierdo, aunque puede también alectar exclusivamente las cámaras derechas del corazón ( $31,33,40$, 123); clínicamente se encuentran signos de insuficiencia cardíaca y soplos mitrales o tricúspideos, que corresponden a alteraciones orgónicas valvulares 0 de tipo funcional $(31,33,34,40,123)$. La alteración anatómica se distingue por afectar el endocardio de zonas vecinas al ápex. que en casos más avanzados se extiende por la cara posterior del venirículo izquierdo hasta afectar la válvala mitral (33, 34, 123). La lesión, macroscópicamente, muestro placas nacaradas en el endocardio ventricular y/o ouricular gue. histológicamente, corresponden a zonas de fibrosis con engrosamiento endocárdico; estas mismas lesiones pueden encon- trarse tombién afectando al miocordio, situación que ha permitido la denominación de endomiocardiofibrosis $(33,34,39$, 40). En nuestra casuística figura el caso No 26, que en vida mostró pocos elementos aparte de un cuadro de insuficiencia cardíaca congestiva que sugirieran el diagnóstico de endomiocardio-fibrosis, sin embargo, en el estudio anatomopatológico se encontró engrosamiento endocárdico y placas nacaradas compatibles con esta entidad. Otros casos de la literatura nacional son reportados por Romero (112), Repelto (111), y el paciente No 3 de la casuística de Lira (90), que por sus características histopatológicas han sido considerados como tal.

La historia natural de las cardiomiopatías es un aspecto todavía no bien conocido, sobre todo, y con razón, en las forinas llamadas idiopáticas, en cambio en otros tipos de cardiomiopatía como la endomiocardio-fibrosis, los estudios integrales permiten que la historia nalural sea algo mejor conocida $(23,33,34)$; puede decirse lo mismo de las formas obstructivas de cardiomiopalía $(19,69)$. Si por historia natural se entiende el conocimiento de una enfermedad desde sus primeras manilestaciones, al referirnos a nuestros casos nos veriamos incapacitados para hablar sobre este punto, pues, prácticamente todos ellos fueron vistos en lo que podría llamarse el períado de estado de la enfermedad y sólo en pocos pudo recogerse información previa al inicio de la sintomatología. A pesar de estas limitaciones y tomando como base la casuística presentada, es posible establecer $\alpha$ lgunas formas clínicas con las cuales la 
BATTILANA G., C. A. Estudio Cínico de Enfermedad Miocárdica Primaria (Cordiomiopatía). Observaciones en 26 casos. An. Med. Univ. N. M. S. M. 54 (3): 262-305, 1971.

Cuadro No 1. Cardiomiopatía. Observaciones en 26 casos, según edad, sexo, hábitos, historia familiar, tiempo y respuesta al tratamiento, evolución y tiempo total de enfermedasl.

\begin{tabular}{|c|c|c|c|c|c|c|c|c|c|}
\hline Casos & Edad & Sexo & Hibitos & $\begin{array}{l}\text { Histatia } \\
\text { Tatiliar }\end{array}$ & $\begin{array}{l}\text { Ticono de } \\
\text { crlemiedad }\end{array}$ & $\begin{array}{l}\text { Cundro } \\
\text { Clínico }\end{array}$ & $\begin{array}{l}\text { Respuesca al } \\
\text { cratrificoto }\end{array}$ & Evolucióo & $\begin{array}{l}\text { Timpo } \\
\text { toral de } \\
\text { cotermedad }\end{array}$ \\
\hline $\begin{array}{l}1 \\
j . C .\end{array}$ & 34 & M & Negativos & Megativa & 9 neses & I.C.C. & Euena & $\begin{array}{l}\text { Alta } \\
\text { Compensado }\end{array}$ & \\
\hline $\begin{array}{r}2 \\
\text { M.O. }\end{array}$ & 53 & $M$ & $\begin{array}{l}\text { Alcohol } \\
\text { For epocas } \\
\text { Delirium } \\
\text { fremens }\end{array}$ & Negativo & 1 mes & $\begin{array}{c}\text { l.C.C.C. } \\
\text { Enbolisio }\end{array}$ & Buena & $\begin{array}{l}\text { Alta } \\
\text { Compensad }\end{array}$ & \\
\hline$\stackrel{3}{R . R .}$ & 16 & 的 & Negativo & Negativo & 9 meses & I.C.C. & Mala & I. C. . ${ }^{++}$ & 12 meses \\
\hline $\begin{array}{c}4 \\
1 . G .\end{array}$ & 38 & 4 & Negativos & $\begin{array}{l}\text { Madre y het- } \\
\text { rianos muer- } \\
\text { tos disl cora } \\
\text { zor. }\end{array}$ & 9 meses & I. C. C. & Hala & $\begin{array}{l}\text { 1. C.1. } \\
\text { misere en } \\
\text { l. C. }\end{array}$ & 19 meses \\
\hline$\stackrel{5}{\text { s. ch. }}$ & 36 & $M$ & $\begin{array}{l}\text { Alcohol } \\
\text { esporádica } \\
\text { mente }\end{array}$ & Negativa & 3 aก̃os & I.C.C. & Euena & $\begin{array}{l}\text { Alta } \\
\text { Compersad. }\end{array}$ & \\
\hline$J_{+}^{6} L$ & 24 & in & Negativa & Negativa & 3 meses & I.C.C. & $\begin{array}{l}\text { Hipersensi- } \\
\text { bilidad a la } \\
\text { digital }\end{array}$ & $\begin{array}{l}\text { Compensado } \\
\text { muerte subi- } \\
\text { ta }\end{array}$ & 5 meses \\
\hline $\begin{array}{c}7 \\
\text { N. L. }\end{array}$ & 14 & u & Negativa & Negativa & 3 meses & I. C. C. & $\begin{array}{l}\text { Hijuersensi- } \\
\text { bilidad a la } \\
\text { Digital }\end{array}$ & $\begin{array}{l}\text { I.C.C. } \\
\text { Mliere an } \\
\text { l.C. }\end{array}$ & 5 meses \\
\hline $\begin{array}{c}8 \\
\text { S. C. }\end{array}$ & 43 & $M$ & $\begin{array}{l}\text { Alcoholis } \\
\text { me crónics } \\
18 \text { ắos. }\end{array}$ & Negativo & 3 meses & I.C.C & Butena & $\begin{array}{l}\text { Alto } \\
\text { ompensor } \\
\text { do }\end{array}$ & \\
\hline${ }^{9}$ क & 65 & $M$ & $\begin{array}{l}\text { Alocoticlino } \\
\text { crónico }\end{array}$ & Negetivo & 12 meses & 1. C. C. & Mala & $\begin{array}{l}\text { I. C.C. } \\
\text { Mtyere En } \\
\text { I.C. }\end{array}$ & 14 meses \\
\hline L.L. & 29 & M & $\begin{array}{l}\text { Alcohol } \\
\text { esporadica- } \\
\text { mente }\end{array}$ & Negediva & 16 meses & 1.C.C. & Euena & $\begin{array}{l}\text { Alta } \\
\text { Compensa } \\
\text { do }\end{array}$ & \\
\hline J.L. & 54 & $B$ & $\begin{array}{l}\text { Alccholismo } \\
\text { crónico } \\
90 \text { años }\end{array}$ & Negativo & 5 meses & I. C. C. & Buena & $\begin{array}{l}\text { Alta } \\
\text { Compensar } \\
\text { dc }\end{array}$ & \\
\hline${ }_{\text {F.N. }}^{12}$ & 51 & st & Negativo & $\begin{array}{l}\text { Madre dia } \\
\text { bética hiper- } \\
\text { tensa }\end{array}$ & 1 año & 1.c.c. & Buena & $\begin{array}{l}\text { Alta. } \\
\text { Compensadd }\end{array}$ & \\
\hline $\begin{array}{c}13 \\
6.5\end{array}$ & 54 & $M$ & $\begin{array}{l}\text { Alcoholis - } \\
\text { mo crónico } \\
36 \text { años }\end{array}$ & $\begin{array}{l}\text { Hijo falleci- } \\
\text { do de Miocar } \\
\text { ditis } 1963\end{array}$ & 4 270s & I.C.C. & Mada & $\begin{array}{l}1 . c . c . \\
\text { Muere } \\
1 . C\end{array}$ & 15 meses \\
\hline $\begin{array}{c}14 \\
\text { S.S.C. }\end{array}$ & 37 & $M$ & Negdiva & Negativa & 4 rieses & I.C.C. & Mala & $\begin{array}{l}\text { J.C.C. } \\
\text { Huere en } \\
\text { I.C.C. }\end{array}$ & I7 Meses \\
\hline
\end{tabular}


BATILANA G., C. A. Estudio Clínico de Enfermsad Miacárdica Primaria (Caraiomiopalia). Observaciones en 26 casos. An. Med. Uriv, N. M. S. M. 54 (3): 262.305. 1971

Cuadro No 1, Cardiomiopatia. Observaciones en 26 casos, según edad, sexo, hábitos, historia familiar, tiempo y respuesta al tratamiento, evolución y tiempo total de enfermedad.

\begin{tabular}{|c|c|c|c|c|c|c|c|c|c|}
\hline CASOS & Edad & Sexo & Hábitos & $\begin{array}{l}\text { Historia } \\
\text { familiar }\end{array}$ & $\begin{array}{l}\text { Tiempo } \\
\text { de en-:it: } \\
\text { fermed. }\end{array}$ & $\begin{array}{l}\text { Cuadro } \\
\text { clírico }\end{array}$ & $\begin{array}{l}\text { Respues- } \\
\text { ta al tra } \\
\text { tamiento }\end{array}$ & $\begin{array}{l}\text { Evolu- } \\
\text { cibn }\end{array}$ & $\begin{array}{l}\text { Tiempo } \\
\text { total de } \\
\text { enfermc }\end{array}$ \\
\hline $\begin{array}{l}15 \\
\text { A.C. }\end{array}$ & 45 & $\mathrm{M}$ & Negativo & Megativo & 6 meses & I. C. C. & Buena & $\begin{array}{l}\text { Alta com } \\
\text { persado }\end{array}$ & \\
\hline $\begin{array}{c}16 \\
C . L .\end{array}$ & 55 & M & Negativo & Negativo & 6 meses & I. C.C. & Mala & $\begin{array}{l}\text { Pide } \\
\text { su alta }\end{array}$ & \\
\hline $\begin{array}{c}17 \\
\text { L. C. }\end{array}$ & 64 & $M$ & $\begin{array}{l}\text { Alcohol } \\
\text { esportai } \\
\text { Eemeri- } \\
\text { Eem }\end{array}$ & Negativo & 6 meses & I. C. C. & Mala & $\begin{array}{l}\mathrm{I}_{6} \mathrm{C.I} . \\
\text { Muere } \\
\text { en I. C. }\end{array}$ & 5 años \\
\hline $\begin{array}{l}18 \\
L . Z\end{array}$ & 50 & M & $\begin{array}{l}\text { Alcoho- } \\
\text { lismo có } \\
\text { nico } 15 \text { a. }\end{array}$ & Negativo & 3 meses & I. C.C. & Buena & $\begin{array}{l}\text { Alta } \\
\text { compen- } \\
\text { sado }\end{array}$ & \\
\hline $\begin{array}{c}19 \\
\text { S. } S, H .\end{array}$ & 60 & M & Negativo & Negativo & 4 meses & I. C. C. & Buena & $\begin{array}{l}\text { Alta } \\
\text { compen- } \\
\text { sado }\end{array}$ & \\
\hline $\begin{array}{l}20 \\
\text { A. G. }\end{array}$ & 38 & $M$ & Negativo & $\begin{array}{l}\text { Madre } y \text { dos } \\
\text { hernianos y } \\
\text { wn bio aries } \\
\text { re nuetentel } \\
\end{array}$ & $\begin{array}{l}2 \text { años } \\
\text { conarig }\end{array}$ & $\begin{array}{l}\text { I. C. } \\
\text { embolis - } \\
\text { mo }\end{array}$ & Mala & $\begin{array}{l}\text { Muerte } \\
\text { súbita }\end{array}$ & $\begin{array}{c}3 \\
\text { años }\end{array}$ \\
\hline c. $G$ & 46 & $F$ & Negativo & 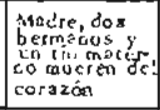 & 6 meses & Embolis. & Mala & Muerte & 8 meses \\
\hline $\begin{array}{l}22 \\
\text { J.L. }\end{array}$ & 35 & $\mathrm{~F}$. & Negativo & Negativo & 1 seman. & I. C. C. & Buena & & \\
\hline$\stackrel{23}{\text { A. Ll. }}$ & 13 & M & Negativo & Niegativ. & 1 mes & $\begin{array}{l}\text { I.C.C. } \\
\text { E.aguda } \\
\text { Embolis. }\end{array}$ & Mala & $\begin{array}{l}\text { I.C.C. } \\
\text { Muere } \\
\text { en I. C. }\end{array}$ & 3 meses \\
\hline $\begin{array}{c}24 \\
\text { S. D. }\end{array}$ & 43 & M & $\begin{array}{l}\text { Alcoho- } \\
\text { lismo } \\
\text { crónico }\end{array}$ & Negativo & 2 seman & I. C.C. & Buena & 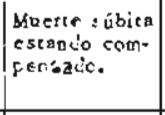 & 7 meses \\
\hline $\begin{array}{c}25 \\
\text { K. M. }\end{array}$ & 41 & $M$ & $\begin{array}{l}\text { Alcoholis } \\
\text { mo crbni } \\
\text { fos } 16 \text { a }= \\
\text { fos }\end{array}$ & Negativo & 14 meses & $\begin{array}{l}\text { I. C.C. } \\
\text { Edema } \\
\text { agudo. }\end{array}$ & Mala & $\begin{array}{l}\text { I. C.C. } \\
\text { Muerte } \\
\text { en I.C. }\end{array}$ & 14 moses \\
\hline${ }^{26}$ L.P. & 45 & $M$ & Negativo & Negativo & 18 meses & I. C.C. & Mala & $\begin{array}{l}\text { Muere } \\
\text { en I. C. }\end{array}$ & 2 años \\
\hline
\end{tabular}

* Es el tiempo transcurrido antes de la 1ra. consulta.

* I.C. Significa Insuficiencia Cardíaca.

+ I.C.C. Significa Insuficiencia Cardiaca Congestiva.

++ I.C.I. Significa Insuficiencia Cardiaca Irreversible. 
Battillana G., C. A. Estudio Clínico de Enfermedad Miocárodica Primaria (Cardiomiopatía). Observaciones en 26 casos. An. Med. Univ. N. M. S. M. 54 (3): 262-305, 1971.

cordiomiopatía puede ofrecerse al médico:

Casos de evolución corta y muerte en insuficiencia cardíaca intratable, Nros. $3,6,7,23$.

Casos con insuficiencia cardíaca fá. cilmente compensados pero con muerte súbita en el período asintomático, No 24. nente, Nros. 4,10 .

Pacientes con manifestaciones hemodinámicas de tipo restrictivo permanente (casos Nros. 4, 10).

Casos con insuficiencia cardíaca fácilmente compensados pero recidivantes, Nros. 1, 11.

Casos sin insuficiencia cardíaca ni cardiomegalia, pero con sintomatología extra-cardíaca, embolismo, No 21.

Además de estas formas clínicas la literatura también menciona pacientes con cardiomegalia que permanecieron asintomáticos por muchos años, como se aprecia en el caso de hipertrofia idiopática descrito por Güeron (70); también es posible la existencia de pacientes con cordiomiopatía e insuficiencia cardíaca de larga evolución. Finalmente, la enfermedad miocárdica primaria puede ser descubierta en personas asintomáticas, con ocasión de exámenes cardiovasculares rutinarios, pero que pueden fallecer súbitamente por arritmias ventriculares (126). En relación a estas formas clínicas, es necesario decir que puede ser difícil el incorporar a una de ellas un paciente dado, que en un determinado ca. so puede presentar dos formas clínicas simultánecmente, $\mathrm{Y}$. que puede pasar rónpidamente en su evolución de una forma a otra. Por estas consideraciones es que resulta difícil establecer el pronóstico de una cardiomiopatía, sin embargo el pre. sente estudio parece indicar que el pronóstico es particularmente sombrío en los pacientes jóvenes.

El tratamiento de las cardiomiopatías es eminentemente médico, siendo éste fundamentalmente sintomático, la digital en la mayoría de casos corrige la insuficiencia cardíaca, pero debe tenerse en cuenta que los pacientes con cordiomio patía pueden presentor mayor sensibilidad $a$ esta droga, por lo que con facilidad se intoxican $(77,136)$, sin embargo, Segal (119), ha encontrado un buen número de enfermos tratados con digital a larga mano y el fenómeno de intolerancia se presentó en una proporción muy reducida de ellos. Es necesario hacer notor que en los casos de estenosis muscuIar sub-aórtica hipertrófica no se aconseja usar esta droga, ya que, debido a su marcado efecto inotrópico produce más bien un agravamiento del cuadro (68). Los diuréticos, así como la restricción do sodio, tienen un electo semejante al encontrado en el tratamiento de cualquier atra cardiopatía por lo que también se re. comienda su empleo (119). Los blo. queadores beta adrenérgicos han demostrado tener cierto efecto para prevenir las arritmias en los casos incipientes de cardiomiopatía (126) y para mejorar la eficiencia cardíaca en las cardiomiopatías obstructivas (65). La quinidina es usada también en los períodos avanzados pero con efectos muy discutibles (119). Algunos autores utilizan anticoagulantes para prevenir los fenómenos embólicos, aunque parece ser que los resultados no son alentadores (119). También se ha considerado el empleo de drogas inmu- 
Battilana G, C, A. Estudio Clínico de Enfermsdad Miocárdica Primaria (Cardiomiopatía). ODservaciones en 26 casos. An. Med. Unlv. N. M. S. M. S4 (3): 262-305, 1971.

nosupresoras, como los corticosteroides, pero su aplicación ha quedado restringidor a los casos con trastomos severos del ritmo, en los que se sospecha una etiología inflamatoria o autoinmune (119).

Desde un punto de vista de cuidado general, ya se ha referido la recomendación de complementar el iratamiento farmacológico con períodos de reposo en cama prolongado, con lo cual se ha logrado, en algunos casos, una reducción notable del tamaño cardíaco. Asimismo, la supresión de la ingesta de alcohol en los estadios tempranos de la cardiopatía alcohólica permitiría la detección o reversión de este proceso $(25,27,28)$. Nues. tra experiencia en el tratamiento ha sido mencionada a propósito de los resultados, en el cuadro $N^{\circ}$. En cuanto a la terapia quirúrgica de la estenosis muscular sub-aórtica hipertrófica existen tres corrientes: los divisores, que propugnan la simple ventriculomiotomía, tratando de escindir los músculos constrictores profundos circulares del tracto de salida del ventrículo izquierdo $(64,100,143)$; otros, los llamados resecadores sugieren procticar resecciones amplias de la musculatura septal ya sea derecha o izquierda para aliviar la obstrucción al flujo de salida $(35,143)$; por último, se menciona también la producción del bloqueo de rama izquierda iatrogénico como otro medio terapéutico de esta afección miocárdica (126). El método que mejores resultados parece ofrecer es el segundo de los mencionados $(35,143)$, ounque en algunas series los resuitados son poco alentadores (67), en otras $(35,64,100,143)$ se puede apreciar, en un buen número de enfermos, el alivio completo de la sinto- matología, siendo los riesgos operatorios y post-operatorios, mínimos (100, 143). Finalmente, en la controversia actual sobre el trasplante cardíaco y sus indicaciones, se ha considerado que los pacientes con cardiopatía ateroesclerótica, que fueron los primeros en quienes se realizó este tratamiento no son los más adecuados para él, ya que el post-operatorio de muchos de ellos esturo complicado por alteraciones metabólicas $\mathrm{y} / \mathrm{o}$ isquémicas en otros territorios, habiéndose incluso observado el desarrollo de ateromatosis coronaria precoz en el corazón injertado en un paciente con cardiopatía aleroesclerótica (133), por lo que quedarían sólo los pacientes con cardiopatía congénito compleja o cardiomiopatía como los candidatos más apropiados para el trasplante cardíaco, ya que en ellos la enfermedad está circunscrita al corazón. aunque de existir una etiología autoinmu. ne ésta podría también afector al órgano trasplantado.

El estudio anatomopatológico de nuestros casos, ya descrito a propósito de los resultados, no permitió una diferenciación morfológica que guardara concordancia con el cuadro clínico, pues el patrón histológico fue más o menos el mismo para todos los pacientes; esta limita. ción del estudio onctomopatológico en las cardiomiopatías ya ha sido mencionada por otros autores, que han dado a entender que el miocardio en una fase final ofrecería una estructura inespecífica común a diferentes etiologías $(21,29$, 98), por lo que podría concluirse que hasta el momento la mictoscopía de luz no ofrece mayor contribución en este campo, salvo el referente a su valor co- 
BATTILANA G., C. A. Estudio Clinico de Eniemedad Miocádica Primaria (Cardiomiopatía). Cbservacionsz en 26 casos. An. Med. Univ. N. M. S. M. 54 (3): 262-305, 1971.

mo elemento confirmatorio del diagnóstico a través de un patrón hisiológico más - menos característico, el cual no permitiría hacer alcances en relación a la etiología en los casos individuales, por el contrario, sería de mayor importancia en algunas cardiomiopatías secundarias, por ejemplo, la amiloidosis.

El tipo de lesión más hallado en nuestros pacientes fue la miocitolisis, lo que corresponde, en términos generales, al tipo I del trabajo de Correa y col. (37). quienes en 18 de sus 28 casos encontraron esta alteración. La microscopía electrónica sí parece ofrecer para algunos autores $(3,4,24,26,78)$ ciertos elementos distintivos en relación a tipos específicos de cardiomiopatías, como es el caso de las alteraciones de las organelas en la cardiomiopatía alcohólica $(3,4,26,78$, 79); tombién los estudios histoquímicos del miocardio, habiéndose encontrado onormalidades de los lípidos y enzimas, pero sin poderse concluir sobre su especificidad $(26,54,79)$.

En vista de las limitaciones de los méiodos anteriormente mencionados en aclarar la etiología de los casos de cardiomiopatía, se pensó que la tasa de anticuerpos anti-músculo miocárdico en los pocientes con cardiomiopatía no fue estadísticamente significativa en comparación con el grupo control formado por pacientes afectos de otras cardiopatías (8): por otra parte, la etiología viral propugnada por algunos auiores $(77,79$ ) iampoco ha podido ser corroborada aún, ya que los títulos de anticuerpos antivirales en el suero de los pacientes con cardiomiopatía no alcanzaron significación estadística en relación al grupo con- trol (56). Finalmente, se ha tratado también de dar a las cardiomiopatías una etiología que estaría relacionada a patrones genéticos tamiliares, habiéndose logrado, incluso por medio de cruces entre roedores, obtener cepas cuya prole desarrolla indefectiblemente insuficiencia cardíaca y miocardiopatía (9), esta teoría se vería reforzada por los numerosos reportes de familias donde un gran núme:O de sus miembros se encuentran atacados de cardiomiopatía, comporlándose en este caso el gen con caracteres dominontes $(20,30,41,83,102,134)$, sin embargo, llama a duda el hecho de que precisamente la mayoría de casos de cardiomiopatía no tenga relación familiar alguna.

\section{CONCLUSIONES}

1. Las cardiomiopatías no son enfermedades raras y la posibilidad de diagnosticarlas está en función de tenerlas presentes, de conocer sus manifestaciones y su capacidad para confundirse con diversas patologías cardiovasculares.

2. Las cardiomiopatías son, en general, procesos crónicos, pero en algunos casos la evolución es sólo de pocas semanas, observación que se ha documentado en pacientes jóvenes en los cuales el pronóstico parece ser más grave. La edad avanzada no debe considerarse impedimento para el diagnóstico, pues éste debe contemplarse en cualquier edad.

3. Estas enfermedades son, como su nombre lo dice, fundamentalmente mio. cárdicas, y sus manifestaciones estón fre- 
BATTILANA G., C. A. Estudio Clínico de Enlermedad Miocárdica Primaria (Cardiomiopalía), Observaciones en 26 casos. An. Med. Univ. N. M. S. M. 54 (3): 262-305, 1971.

cuentemente relacionadas $\alpha$ insuficiencia cardiaca, pero, en oportunidades, la sintomatología inicial puede ser por compromiso embólico de diferentes territorios orteriales.

4. La etiología de estos procesos es variada y todaría mal conocida a pesar del empleo de técnicas diagnósticas modernas como son, la microscopía electrónica, histoquímica $\theta$ inmunopatología.

5. El diagnóstico de estas enfermedades es esencialmente clínico cuando ellas alcanzon el período de estado, pero en pacientes asintomáticos la manera re comendable de detectarlas parece ser a través de encuestas radiológicas y electrocardiográficas.

6. Es Iecomendable el estudio del grupo fomilias una vez que se establece el diagnóstico de una cardiomiopatía, por la existencia de las formas familiares.

7. El método auxiliar de mayor ayuda en el diagnóstico parece ser el elec. trocardiograma que, aunque no proporciona patrones especificos, puede sugerir la existencia de una cardiomiopatía a través de un conjunto de alteraciones.

8. Aunque el grupo estudiado no fue numeroso, estuvo compuesto por pacientes originarios de diferentes regiones del país, indicando que las cardiomiopatías aporentemente están distribuidas en forma amplia en nuestro territorio.

9. La enfermedad de Chagas no fue detectada en ninguno de los 10 pacientes en los cuales fue especificamente investigada, de lo que se concluiría que no es uno etiología importante de cardiomiopatía, o que ella estaría circunscrita a ciertas localidades del país.

10. El cuadro clínico frecuentemen- te no guarda concordancia con los hallazgos anatomopatológicos, y es así como, a pesar de haber considerado en nuestro estudio varios grupos etiológicos, el patrón histológico encontrado fue semejante en muchos de ellos, habiéndose caracterizado por miocitolisis y alteraciones nucleares.

11. En el periodo de estado de las cardiomiopatías el pronóstico es malo y el tratamiento es limitado, por lo que es recomendable la identificación de los casos asintomáticos, en quienes las medidas terapéuticas pueden ofrecer mayores posibilidades.

12. Como se ha dicho, las cardiomiopatías no deben considerarse como enfermedades raras y aunque el conocimiento que de ellas tenemos es todavía insuficiente, debe insistirse en su estudio con el objeto de adquirir mayor información acerca de ellas, así como para de terminar su importancia como factor de morbilidad en nuestro país.

\section{REFERENCIAS}

1. Aldinger, E. E. y Maines, H. E.: Myocardial depressión accompanyng chro. nic consumption of alcohol. Amer. Heart J. 73: 55-62, 1967.

2. Alexander, C. S.: Idiopathic heart disease. I: Analysis of 100 cases, with special reference to chronic alcoholism. Amer. J, Med. 41: 213-228, 1966.

3. - Idiopathic heart disease II: Electron microscopic examination of myocardial biopsy specimens in alcoholic heart disease. Amer. J. Med. 41: $229-234,1966$

4. - Electron microscopic observations in alcoholic heart disease. Brit. Heart J. 29: 200-205, 1967. 
BatTilaNA G., C. A, Estudio Clínico de Eniermedad Miocárdica Primaria (Cardiomiopatía), Ob. servaciones en 28 casos. An. Med. Univ. N. M. S. M. 54 (3): 262-305, 1971.

5. Cobalt and the heart. Ann. Int. Med. 70: 411-413,1970.

6. Andrade, Z, y Guimaraes, A. C.: Endomyocardial fibrosis in Bahia, Brasil. Brit. Heart J. 26: 813-820, 1964.

7. Alzamora, R.: Case de miocarditis chagásica observado en Lima en Noviembre de 1928. Rev. Per. de Cardiol. 7: $327-332,1958$

8. Arribada, A. y Escobar, C.: Toxoplasma gondii and cardiomyopathy, Amer. J. Cardiol. 1: 610, 1958.

9. Bajusz, E.: Hereditary cardiomyopathy. A new disease model. Amer. Heart. J. 77: 686-695, 1959.

10. Balchum, O. J.; MeCord, M. C. y Blount, S. G.: The clinical and hemodynamic pattern in nonspecific myocarditis. A comparison with other entities also impairing myocardial efficincy. Amer. Heart J. 52: 430-443, 1956.

11. Barritt, D. y Al-Shamma'a, M.: Hears iailure from unexplained cardiomyopathy. Brit. Heart J. 28: 674-689, 1966.

12. Bashour, F. y Winchell, P.: Post-partal heart disease. A syndrome? Ann. Int. Med, 40: 803-808, 1954

13. Battersby, E. y Glenner, G.: Familial cardiomyopathy, Amer. J. Med. 30: $382-391,1961$.

14. Benchimol, A.; Legler, J. y Dimond, $G .:$ The carotid tracing and apexcardiogram in subaortic stenosis and idiopathic myocardial hypertrophy. Amer. J. Cardiol. 11: $427-435,1963$.

15. Blankenhorn, $M$. A. y Gall, E.: Myocarditis and miocardosis. A clinicopathologic appraisal. Circulation 13: $217-223,1956$

16. Bloomfield, D, y Liebman, J.: Idiopathic cardiomyopathy in children. Circulation 27: 1071-1077, 1963

17. Bourdarias, J.; Ourbak, P.; Ferrane, J.; Sozutek, Y. y Lenegre, J.: Obstructive cardiomyopathy. Cineangiocardiographic study of 50 cases. Amer. J. Roentgenol. 102: 853-864, 1968.

18. Braunwald, E.; Morrow, G. A.; Cor- nell, P. W.; Aygen, M. M. y Hilbish, F. T.: Idiopathic hypertrophic subaortic stenosis. Amer. J. Med. 29: $924-945,1960$.

19. Braunwald, E.: Idiopathic Hypertrophic subaortic stenosis, Circulation 37: 759-788, 1968

20. Brent, L.; Fisher, D. y Taylor, W.: Familial muscular subaortic stenosis. Circulation 20: 676, 1959

21. Bridgen, W.: Uncommon myocardial diseases. Lancet. 273: 1179-1184, 1957.

22. Bridgen, W. y Robinson, I.: Alcoholic heart disease. Brit. ed. J. 2: 12831289,1904 .

23. Brown, A.; Donkas, N.; Riding, W. y Wyn, J.: Cardiomyopathy and pregnancy. Brit. Heart. J. 29: 387, 1967.

24. Burch, G. E. y Walsh, J.: Cardiac insufficiency in chronic alcoholism. Amer. J. Cardiol, 6: 864, 1969.

25. Burch, G. E.; Walsh, J. y Black, W.: Value of prolonged bed rest in manegement of cardiomegaly JAMA 183: 81-87, 1963

26. Burch, G. y de Pasquale, N.: Alcoholic cardiomyopathy. Cardiología 52: 48, 1968.

27. Burch, G. E. y de Pasquale, N. P.: Alcoholic cardiomyopathy. Amer. J. Cardiol. 23: 723, 1969.

28. Burch, G. E.; Mc Donald, C. y WaIsh, J.: The effect of prolonged bed rest on post-partal myocardiopathy. Amer. Heart J. 81: 186, 1971.

29. Burwell, S. y Robin, E.: Diagnosis of diffuse myocardial fibrosis Circulation 20: 606-614, 1959

30. Campbell, M. y Turner-Warwick, M.: Two more families with cardiomegaly. Brit. Heart J. 18: 393-402, 1956.

31. Cardiomiopatías: Boletín del Organismo Mundial de la Salud. 33: 257, 1965.

32. Clark, G. M.; Valentine, E. y Blint, S. G.: Endocardial fibrosis simulating constrictive pericarditis. Report of a case with determinations of pressure in the right side of the heart and 
BATTLANA G., C. A. Esludio Clinico de Entermpdad Miocárdica Primaria (Cardiomiopalia). Observaciones en 26 cascs. An. Med. Univ. N. M. S. M. 54 (3): 262.305. 1971.

eosinophilia. New Eng. J. Med, : 254: $349,1956$.

33. Connor, D. H.; Somers, K.; Hutt, M. S. R.; Manion, W. y D'Arbela, P. G.: Endomyocardial fibrosis in Uganda (Davies' disease). Part I. An epidemiologic, clinical and pathologic study. Amer. Heart J. 74: 687-709, 1967.

34. : Endomyocardial fibrosis in Uganda (Davies' disease). Part II. Amer. Heart J. 75: 107-123, 1968.

35. Cooley, D.; Bloodwell, R, Hallman. G.: La Sorte, A.; Leachman, R. y Chapman, D.: Surgical treatment of nuscular subaortic stenosis. Results from septectomy in twenty six patients. Circulation, Sup. I: 33: 124-132, 1967.

35. Comejo Donayre, A.; Cubas, E.; Eyzagidire, $G$.; Dominguez, P.; Bitrich, H.; Gómez, R. y Cornejo, J.: Enfermedad de Chagas en el Sur del Perú. Estudio epidemiológico, clinico, electrocardiográfico y profiláctico. Anales de la Fac. de Med. 46: 587-609, 1963.

37. Correa, P. ; Restrepo, C.; García, C. y Quiroz, A. C.: Pathology of heart diseases of undetermined etiology which occur in Cali, Colombia. Amer. Heart J. 66: $584-595,1953$.

38. Das, S. y Dodson, V.: Inmunoglobulin binding in cardiomyopalhic heart. Circulation 40: Sup. 1II, 66, 1969.

39. Davies, H, y Evans, W.: The significance of Deep $S$ Waves in leads II and IIf. Brit. Heart J. 22: 551-561, 1960.

40. Davies, J, N, P.: Some considerations regarding obscure diseases affecting the mural endocardium. Amer. Heart J. 59: 600-628, 1960 .

41. Davies, L. G.: A family heart disease. Brit. Heart J. 14: 206-212, 1952.

42. Davies, R. R.: Marvel, R. J. y Genovese, $P$. D. : Heart discase of unknown etiology. Amer. Heart J 42: 546, 1951.

43. Doane, J. C. y Skversky, N. J.: Massive Cardiac Hipertropyh. Amer. Heart J. 28: 816-818, 1944.

44. Durrer, D.; Schuilenburg, R. y Wel- lens, J.: Pre-excitacion revisited. Amer. J. Cardiol. 25: 690-697, 1970

45. Dye, C. L.; Rosenbaum, D.; Lowe, J.; Behnke, R. H. y Genovese, P. D.: Primary myocardial disease Part I: Clinical features. Ann. Int. Med. 58: 426-441, 1963.

46. Edington y Hutt, M, S. R.: Idiopathic cardiomegaly. Cardiologia. 52: 33 , 1968.

47. Elster, S, K, ; Horn, H. y Tuchman, L. R.: Cardiac hipertrophy and insufficiency of unknown etiology. Amer. J. Med. 18: 900-921, 1955.

48. Escomel, E.: La trypanosomiasis humaine exists dans les forts orientalis du Perou. Bull. Soc. Pat. Exat. París. 12: 723, 1919. Citado por Cornejo Donayre y col. (36).

49. Espinoza, J.: Pericarditis constrictiva. Tesis de $\mathrm{Br}$. Prog. Académico de $\mathrm{Me}$. dicina. U.N.M.S.M. 1969, Lima.

50. Evans, W.: Alcoholic cardiomyopathy. Amer. Henrt J. 61: 566-567, 1961

51. - Alcoholic cardiomyopathy. Prog. Cardiovasc. Dis. 7: 151, 1964.

52. Ewy, G. A.; Ríos, J. C. y Marcus, F. I.: The dicrotic arterial pulse. Circulation 39: 655-661, 1969.

53. Fefjar, Z.: Cardiomyopathies. An international problem. Cardiologia. 52: 9, 1968.

54. Ferrans, V.: Alcoholic cardiomyopathy. Histochemical study, Amer. Heart J. 69: 748-763, 1965 .

55. Fishleder, B. L.: Exploración cardiovascular y fonomecanocardiografía clinica. La Prensa Médica Mexicana. pág. 7I1, México, 1966.

56. Fletcher, G.; Coleman, N.; Fecrino, P.; Marine, $W . y$ Wengwe, N.: Viral antibodies in patients with primary myocardial disease. Amer. J. Cardiol. 21: 6-10, 1968 .

57. Forbes, G. y Bradley, A.: Idiopathic cardiomegaly. Brit. Med. J. 2: 1125$1123,1960$.

58. Fowler, N.; Gueron, M. y Rowlands, 
BATTILANA G., C. A. Estudio Clínico de Enferm zdad Miocóndica Primaria (Cardiomiopatía). Observaciones en 26 casos. An. Med. Univ. N. M. S. M. 54 (3): 262-305. 1971.

D.: Primary myocardial disease. Circulation 23: 498-508, 1961.

59. - Primary myocardial disease. Dis. Chest, 41: 593, 1962.

60. Fowler, N.: Classification and differencial diagnosis of the myocardiopathies. Prog. Cardiovasc. Dis. 7; 1 , 1964.

61. Fowler, N. y Gueron, M.: Primary myocardial disease. Circulation 32: 830-836, 1965.

62. Friedberg, C. K.: Diseases of the heart. Third edit. pág. 992. W. B. Saunders Co. Philadelphia y Londres, 1986.

63. Friedrich, N.: Handbuch der speziallen pathologic und therapic. Fifth section: Die krankheiten des herzens. Verlag von Ferdinand Enke. Erlangen, 1861, Citado por Massumi, R. (94)

64. Frye, R.; Kincaid, O.; Swan, H. y Kirklin, J.: Results of surgical treatment of patients with diffuse subvalvular aortic stenosis. Circulation 32: 52-57, 1905.

65. Gillanders, A. D.: Nutritional heart disease. Brit. Heart J. 13: 177-195, 1951.

66. Gocdhart, R. y Jolliffe, N.: The role of nutritional deficiencies in the production of cardiovascular disturbances in the alcohol addicts. Amer. Heart J. 15: 569-586, 1938.

67. Goodwin, J.; Gordon, H.; Hollman, A. y Bishop, M.: Clinical aspects of the cardiomyopathy. Brit. Med. J. 1: 69,1961

68. Goodwin, J.: Obstructive cardiomyopathy. Cardiologia 52: 69, 1968.

69. Gooawin, J. F.: Congestive and hypertrophic cardiomyopathies. Lancet 1: 731,1970 .

70. Gueron, M.: Idiopathic cardiac hipertrophy of long duration. Amer. Heart J. 59: $446-452,1960$.

71. Hamby, R, y Raia, F.: Electrocardiographic aspects of primary myocardial disease in 60 patients. Amer. Heart $\mathbf{J}$. 76: 316-328, 1968.

72. Hamby, R. y Raia, F.: Vectocardio- graphic aspects of primary myocardial disease in 50 patients. Amer. Heart J. 76: 304-315, 1968.

73. Hamby, R.: Primary myocardial disease. A prospective clinical and hemodinamic evolution in 100 patients. Medicine 49: 55, 1970 .

74. Hamby, R.; Catangay, P.; Apiado, O. y Hafiz Khan, A.: Clinical, hemodynamic and angiocardiographic correlates in 50 patients with primary myocardial disease. Amer. J. Cardiol. 25: $625-633,1970$.

75. Harris, L. C.; Rodin, E. y Nghiem, Q.: Idiopathic nonobstructive cardiomycpathy in children. Amer. J. Cardiol, 21: 153-165, 1968.

76. Harvey, P. W. y Perloff, J.: The auscultatory findings in primary myocardial disease. Amer. Heart J. 61: 199205, 1961

77. Harvey, W.; Segal, P. y Gurel, T.: The elinical spectrum of primary myocardial disease. $7: 17,1964$

78. Hibbs, R.; Ferrands, V.; Black, W.; Walsh, J. y Burch, G.: Alcoholic cardiomyopathy. An electron microscopic study. Amer. Heart J. 69: 766-779, 1965 .

79. heart of a patient with cardiomyopathy. An electron microscopic and histochemical study. Amer. Heart J. 69: $327-337,1965$.

80. Hollister, R. M. y Goodwin, J. F.: The electrocardiogram in cardiomyopathy. Brit. Heart J. 25: 357-374, 1965.

81. Introduction to the Cardiomyopathies. International Society of Cardiology. Edit. by A. G. Shaper. Switzerland, 1968 .

82. Josserand, E. y Gallavardin, L.: De l'asystolie progresive des jeunes suiets par myocardite subsigue primitive. Arch. Gen. de Med. 6: 513, 1901. (Fotocopia en la Hemeroteca del Prog. Acad. de Medicina).

83. Kariv, I.; Sherf, L. y Solomon, M.: Familial cardiomyopathy. With special 
BATTILANA G., C. A. Estudio Clinico de Enfermedad Miocárdica Primario (Cardiomiopatía). Observaciones en 26 casos. An. Med. Univ. N. M. S. M. 54 (3): 262-305, 1971.

consideration of electrocardiographic and vectocardiographic findings. Amer. J. Cardiol, 13: 734-749, 1964.

84. Kline, I. y Saphir, O.; Chronic pernicious myocarditis. Amer. Heart J. 59: $681-697,1960$.

85. Laubry, C. y Walser, J.: Sur un cas de l'insuffisance cardiaque primitive, les myocardies. Bull. et Mém. Soc. Med. Hop. Paris. 49: 409, 1925.

86. Levy, R. L. y Orusselot, L. M.: Cardiac hypertrophy of unknown etiology in young adults. A clinical and pathological study of three cases. Amer. Heart J. 9: 178-195, 1933.

87. Levin, E. B. y Cohen, S. L.: Idiopathic myocardial hypertrophy simulating reumathic heart disease. Amer Heart J. 48: 637-640, 1954.

88. Levy, R. L. y Von Glahn, W. C. : Cardiac hypertrophy of unknown cause. Amer. Heart J. 28: 714-741, 1944.

89. Languer, P. H. y Lauer, J. A.: The relative significance of high-frequency and low-frequency notching in the electrocardiogram. Amer. Heart J. 71: $34-42,1966$.

90. Lira, C. J .: Cardiomiopatías en las autopsias del Instituto de Patología de la U.N.M.S.M. (1961-1970). Estudio anatomo-clínico de las cardiopatías de etiología oscura. Tesis de $\mathrm{Br}$. Prog. Acad. de Medicina Humana. U.N.M. S.M. Lima, 1970

91. Marcus, F. I.; Gómez, L.; Glancy, L.; Ewy, G. A. y Roberts, W.: Papilary muscle fibrosis in primary myocardial disease. Amer Heart J. 77: 681-685. 1969 .

92. Marriot, H.: Electrocardiographic abnormalities, conduction disorders and arrhytmias in primary myocardial dissease. Prog. Cardiovasc. Dis. 7: 99, 1964.

93. Massie, E. y Walsh, T. J.: Clinical vectocardiography. Chicago Year Book Publishers. 1960.

94. Massumi, A. R.: Primary myocardial disease. Report of fifty cases and re- view of the subject. Circulation. 31: 1941, 1965 .

95. Mattingly, T.: Clinical features and diagnosis of primary myocardial disease. Mod. Concepts Cardiovasc. Dis. 30: 676,1961 .

96. Changing concepts of myocardial diseases. JAMA. 191: $33-37$, 1965 .

97. - Primary myocardial disease in middle age and older. Geriatrics 22: $135,1967$.

98. - Disease of myocardium. Amer. J. Cardiol, 25: 79-80, 1970.

99. Mohinddin, S.; Taskar, P.; Rheault, M. ; Roy, P. E.; Chenard, J. y Morin, Y.: Experimental Cobalt cardiomyopathy. Amer. Heart J. 80: 532-543, 1970.

100. Morrow, A.; Fogarty, T.; Hannah, H. y Braunwald, E.: Operative treament in idiopathic subaortic stenosis. Circulation. Sup. I: 33: 124, 1967.

101. Nagaratman, N. y Dissanayake, R.: Endomyocardial fibrosis in the Ceylonese. Brit. Heart J. 21: 167-173, 1959.

102. Pare, J.; Fraser, R.; Pirozynsky, W.; Shanks, J. y Stubington, D.: Hereditary cardiovascular dysplasia. Amer. J. Med. 31: 37-62, 196I.

103. Peralta, A.: Clinica de la miocarditis chagásica. Revista del Viernes Médico. 9: 1, 1958.

104. Pereda, S. y Domínguez, P.: Segundo Congreso Peruano de Cardiología. Li. ma, 1965 .

105. Pruitt, D. D.; Curd, G. W. Jr. y Leachman, R.: Simulation of electrocardiogram of apicolateral myocardial infarction by myocardial destructive lesions of obscure etiology (myocardiopathy). Circulation 15: 506-514, 1962.

106. Ramalingaswami, V.: Nutrition and the heart. Cardiología: 52: 57, 1968.

107. Ramsey, R.; Sbar, S.; Elliott, L. y Eliot, R.: The differential diagnosis of restrictive myocardiopathy and chronic constrictive pericarditis without calcification. Value of coronary arte- 


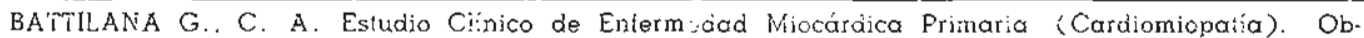
servaciones en 26 casos. An. Med. Unir. N. M. S. M. 54 (3): 262.305, 1971.

rjography. Amer. J. Cardiol, 25: 635638,1970

108. Regan. T. J.: Koroxenidis, G. y Moschos. C. B.: Acute metabolic and hemodynamic response of the left ventricle to ethanol. L. Clin. Invest. 45: 270,196

109. Regan, T.: Levinson, G. y Aldewentel, $\mathrm{H}$.: Ventricular function in non cardiac with alcoholic fatty liver. Role of ethanol in the production of cardio. myopathy. $J$. Clin. Invest. 48: 397, 1969.

110. Reisinger. J. A. y Blumenthal, B.: Myocardial degeneration with a hypertrophy and failure of unknown causes. Amner. Heart J. 22: 822, 1941.

111. Repcato, M.: Fibrosis endomiocárdica; estudio clínico y comprobación anatomopatológica acerca de un caso presentado en el Hospital Obrero de Lima, Tesis Br. 5336. Prog. Acad de Medicina Humana. U.N.M.S.M. Lima, 1962 .

112. Romero, O. E.: Contribucion al estudio ae la endomiocardiofibrosis. Tesis $\mathrm{Br}$. 4485. Prog. Acad de Medicina Humana, U.N.M.S.M. Lima, 1958.

113. Rosenbaum, M.: Elizari, M.; Lazzari, J.; Nau, G.: Levi, R. y Halperius, S.: Intraventicular trifascicular blocks. Review of the literature and classifi. cation. Amer. Heart J. 78: 450, 1969.

114. Rosenbaum, M.: Los hemibloqueos: criterios diagnosticos y significación clinica. Conceplos modernos de las enfermedades cardiovasculares. 39: 81, 1970 .

115. Sackner, M. A.; Lewis, D. H.; Robinson, M. J. y Bellet, S.: Idiopathic myocardial hypertrophy. Amer J. Cardiol. 7: 714, 1961.

116. Sanders. V.: Idiopathic disease of the myocardium. Arch. Int. Med. 112: 75, 1963

117. Schrader, W.: Pankey, G.; Davis, R. $y$ Theologides, A.: Familial idiopatinic cardiomegaly. Circulation 24: 599-606. 1961
118. Schrire, V.: Racial incidence of heart disease at Groote Schur Hospital. Part III: The less common forms of heart disease. Amer. Heart J. 55: 835, 1960.

119. Segal. J.; Harvey, P. y Gurel, T': Diagnosis and treament of primary myocardial disease. Circulation 32: 837,1965 .

120. Shabetai, R, y McGuire, J.: Idiopathic cardiac hypertrophy simulating valvular heart disease. Amer, Heart J, 65: 124-130. 1963 .

121. Shabetai. R.; Fowler, N. y Fenton, J.: Restrictive cardiac disesse. Pericarditis and Myocardiopathies. Amer. Heallt J. 69: 27l-280, 1965.

122. Shah, P. M.; Amarasingham, R. $y$ Cakley, C. M.: Hemodynamic effects of changes in blood volume in hypertrophic obsiructive cardiomyopathy. Brit. Heart J. 27: 83-89, 1965.

123. Shaper, A. C.: Endomyocarclial fibrosis. Cardjologia 52: 20, 1968

124. Smith, J. D. y Furth, I.: Fibrosis of the endocardium and the myocardium with mural thrombosis. Arc. Int. Med. 71: $602,1943$.

125. Sommers, B.: Problems in clinical diagnosis and classification of ventricular hypertrophy. Minnesota Med. 39: 12, 1956. Citado por Maruiot (45).

126. Sowton, E. : Segundo Congreso de Medicina y Seguridad Social. Hospital Obrero de Lima. (Symposium de Cardiomiopatias). Lima, 1971.

127. Spocijck, D. H. y Littman, D.: Idiopathic myocardial hypertrophy. Amer. J. Calciol, 1: 610, 1958.

128. Steel, G.: Heart failure as a result of chronic alcoholism. Med. Chronic. Manchester 18: 1, 1893. Citado por Massumi (94).

129. Strumpell, A.: A textbook of medicine. Transl. by Vickery H. F. Knapp. P. D. Appleton Co. New York, 1888, Citado por Massumi (94).

130. Stuart, K. L.: Pelipartal cardiomyopathy. Cardiologia. 52: 44, 1968.

131. Sutton, G.; Driscoll, J.; Gunnar, R. y 
BAtTIlANA G., C. A. Esludio Clínico de Entermedad Miocárdica Primaria (Cardiomiopalía). Observaciones en 26 casos. An. Med. Univ. N. M. S. M. 54 (3): 262-305, 1971.

Tobin, J.: Exploratory mediastinotomy in primary myocardial disease. Prog. Cardiovasc. Dis. 7: 83, 1964.

132. Theologides, H. y Kennedy, B.: Toxoplasmic myocarditis and pericarditis. Amer, J. Med. 47: 169-174, 1969.

133. Thompson, J. G.: Production of severe ateroma in transplanted human heart. Lancet 2: 1088, 1969.

134. Treger, A. y Blount, G.: Familial cardiomyopathy. Amer. Heart. J. 70: $40-53,1965$.

135. Voigt, G. y Friesinger, R.: Apexcardiography in left ventricular diastolic pressure. Circulation. 41: 1015, 1970 .

136. Von Bonsdorff, B.: Myocardial disease of obscure origin. Acta Med. Scand. 100: 403, 1939.

137. Walsh, J.; Burch, G.; Black, W.; Ferrans, J. y Hibbs, R.: Idiopathic Myocardiopathy of puerperium (Postpartal heart disease). Circulation 32: 19-31, 1965.

138. Ware, E. R. y Chapman, B. M.: Chronic fibroplastic myocarditis. Amer Heart J. 33: 530-537, 1947.

139. Weber, D. J.; Gould, L. y Shaffer, A.
I.: A family with idiopathic myocardial hypertrophy. Amer. J. Cardiol. 17: 419-425, 1966.

140. Webb, W, y Degerli, U .: Ethyl alcohol and the cardiovascular system. JAMA. 191: 1055-1058, 1965.

141. Wendt, $V$. et al.: Hemodynamic and metabolic effects of chronic alcoholism in man. Amer. J. Cardiol. 15: 175183,1965 .

142. Westlake, R.; Cohen, W, y Willis, W. H.: Wolf-Parisinson-White syndrome and familial cardiomegaly. Amer. Heart J. 64: 314-320, 1962.

143. Wigle, E. D.; Trimble, A. S.; Adelman, A. G. y Bigelow, W.: Cirugía en la stenosis subaórtica muscular. En Progresos de las Enfermedades Cardiovasculares. Friedberg, C. K. IX, pág. 93. Edit. Científico Médica, 1969.

144. Wood, P.: Chronic constrictive pericarditis. Amer. J. Cardiol. 7: 48, 1961.

145. Yu, P.; Cohen, J.; Schreiner, B. y Menphy, G.: Hemodynamic alterations in primary myocardial diseases. Prog. Cardiovasc. Dis. 7: 125, 1964.

146. Zarco, P.: Exploración clínica del corazón. Edit. Alhambra. España, 1961. 